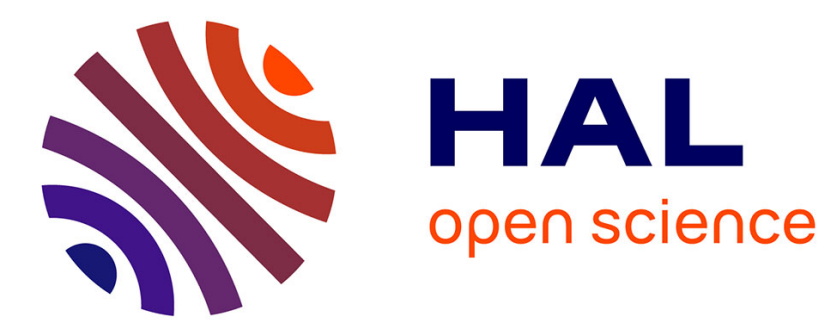

\title{
Damping behavior of plant fiber composites: A review
}

Taiqu Liu, Pauline Butaud, Vincent Placet, Morvan Ouisse

\section{To cite this version:}

Taiqu Liu, Pauline Butaud, Vincent Placet, Morvan Ouisse. Damping behavior of plant fiber composites: A review. Composite Structures, 2021, 275, pp.114392 (14). hal-03427017

\section{HAL Id: hal-03427017 https://hal.science/hal-03427017}

Submitted on 12 Nov 2021

HAL is a multi-disciplinary open access archive for the deposit and dissemination of scientific research documents, whether they are published or not. The documents may come from teaching and research institutions in France or abroad, or from public or private research centers.
L'archive ouverte pluridisciplinaire HAL, est destinée au dépôt et à la diffusion de documents scientifiques de niveau recherche, publiés ou non, émanant des établissements d'enseignement et de recherche français ou étrangers, des laboratoires publics ou privés. 


\title{
Damping behavior of plant fiber composites: a review
}

Taiqu Liu, Pauline Butaud, Vincent Placet, Morvan Ouisse

FEMTO-ST Institute, CNRS/UFC/ENSMM/UTBM, Department of Applied Mechanics, Univ. Bourgogne Franche-Comté, F-25000, Besançon, France

\begin{abstract}
This paper reviews the damping characteristics of plant fiber composites (PFCs) with a particular attention regarding their performances with respect to synthetic fiber composites (SFCs). Indeed, PFCs become more and more popular in many application fields. Their specificities when compared to synthetic fibers, such as glass fibers, make them good candidate to improve the damping behavior of composite materials and structures. The influence of meso and micro scale parameters as well as surrounding conditions is reviewed in the present paper. Contradictory reports are sometimes found and the existing knowledge on the damping behavior of PFCs is sometimes deficient or ambiguous. Some key points like variability, hierarchical aspects and sensitivity of the mechanical properties are thus discussed. This review provides a first reference for the factors that affect damping properties in PFCs to be used in engineering applications in various fields including automotive, aerospace, music devices. It also highlights the current shortcomings on knowledge on damping of PFCs. The Ashby diagram built from the data available in literature constitutes a first tool to select materials considering the compromise between loss factor and stiffness that can be used for engineering design considerations.
\end{abstract}

Keywords: Damping; Loss factor; Dynamic mechanical analysis; Plant fiber; Composites; Energy dissipation 


\section{Contents}

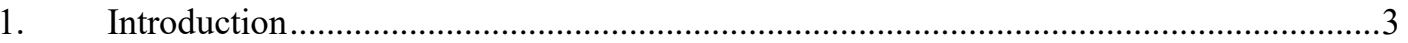

2. On the experimental techniques for the characterization of composite damping .............7

2.1 Quasi-static and low frequency characterization: DMA ............................................

2.2 Low to mid-frequency characterization: modal analysis ............................................. 8

2.3 High frequency characterization: wave number-based approaches ..............................

3. Review of studies on the damping behavior of PFCs ..................................................

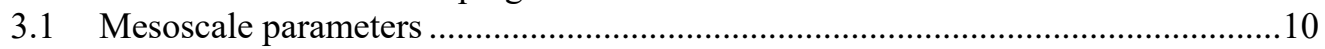

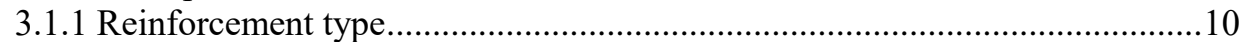

3.1.2 Stacking sequence.................................................................................12

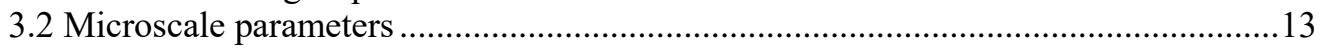

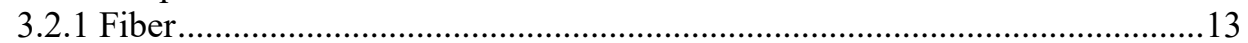

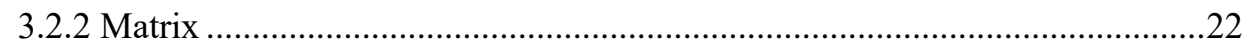

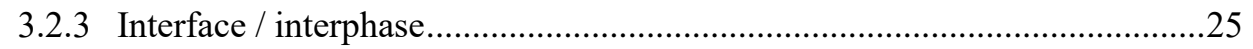

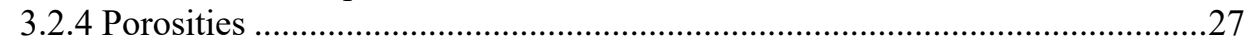

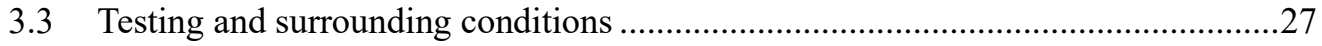

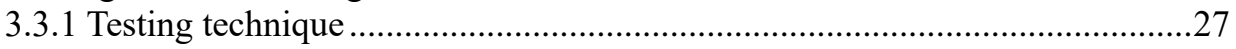

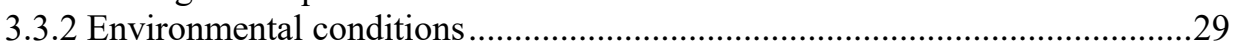

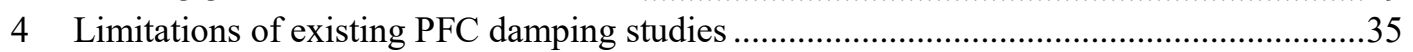

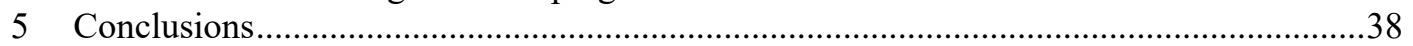

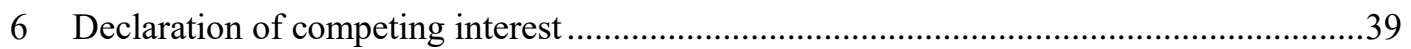

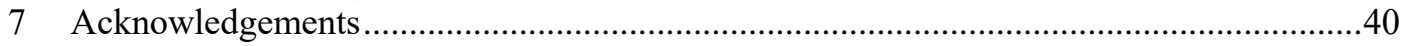

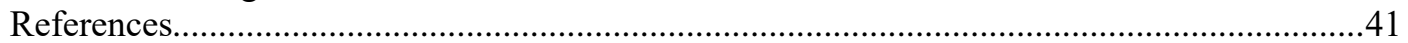

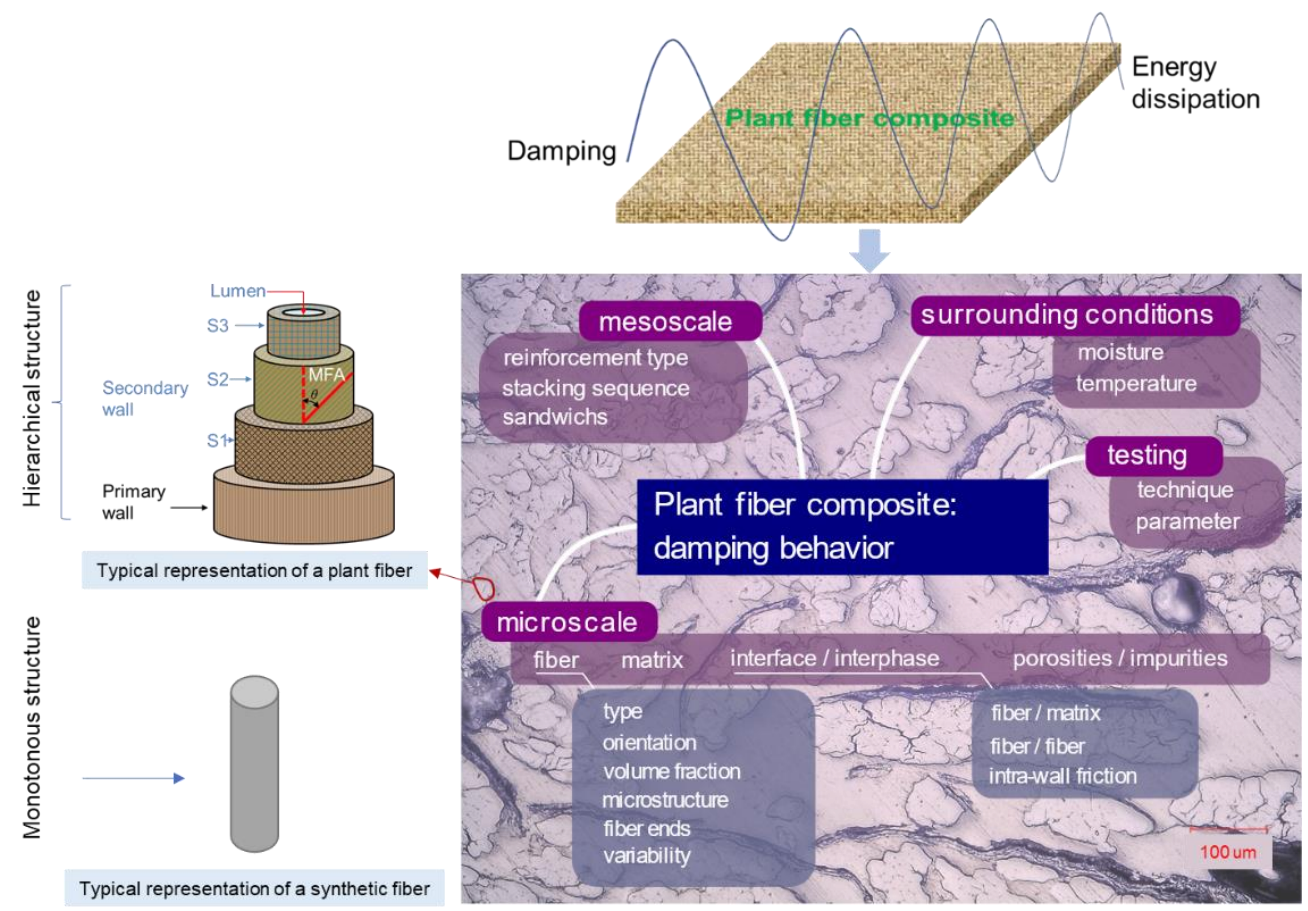

Figure. 1 Graphical abstract 


\section{Introduction}

The invention of mechanical equipment accelerated the process of industrial development. Human requirements for machinery were not limited to high-efficiency characteristics but began to pay more attention to comfort performances and safety. Therefore, engineers began to look for different kinds of damping materials to reduce the effects of vibration and noise [1,2]. The use of damping materials improves people's living and working conditions and creates quiet and comfortable surroundings. With the development of the petrochemical industry, the oil began to expand from the original fuel source to the use of by-products [3-5]. Resins, asphalt, and rubber began to enter the industrial field of large-scale applications, especially for reducing vibration [6]. However, they cannot be used alone due to their low stiffness. In most cases, they are used together with wood or metal sheets in sandwich structures to make up for the shortcomings of each other. A sandwich structure has characteristics of sound insulation and vibration damping, which cannot be provided by a single material in addition to the strength properties compared with pure wood board or metal plate [7-10]. With the development of highstrength fibers such as glass fibers and carbon fibers, attempts have been made to mix fibers and polymers in a specific ratio to manufacture fiber-reinforced composites [11]. It has been found that this type of material has outstanding performances in specific strength, specific modulus, fatigue strength, impact resistance, damping and devisable characteristics than pure metal material or polymers [12,13]. In particular, people currently want to reduce energy consumption by using some lightweight materials, and 
the advantages of composite materials in this respect make it a significant trend to replace traditional materials, especially in the fields of aerospace, transportation, wind power, etc. [14-16]. Many studies have focused on increasing strength, modulus, and enhanced crashworthiness as structural components when composite materials began to be of interest [17]. At present, composite materials are also intended to improve the damping performances of the structures while retaining the other primary structural functions.

However, the large-scale application of petroleum-based compounds has also brought about some adverse effects. Engineers should now consider environmental impact at each stage of the life cycle during the implementation of damping materials since petroleum-based products are difficult to be degraded by nature [18]. Plant fibers become more and more concerned because of abundant reserves, while being renewable, low cost, quickly obtained and processed, degradable, lightweight, possess relatively high specific modulus, and other advantages $[3,18-20]$. The properties of many plant fibers coming from hemp, flax, jute, ramie, kenaf, banana, agave, doum palm, pine cone, etc. are investigated [21-24]. Plant fibers become a sustainable material of choice in automotive, aerospace, musical instruments, and other applications. In particular, their role in automotive parts includes ceilings, coat racks, seatbacks, instrument panels $[25,26]$. Up to now, plant fiber-reinforced composites (PFCs) have been mainly used for mass saving as a low-cost and sustainable solution. PFCs can also overcome the mechanical and physico-chemical properties of conventional composite materials to a certain extent, and they could solve some critical problems that cannot be addressed by traditional 
materials in engineering structures. Some of their intrinsic properties, for instance their natural damping, can be exploited to implement new and advanced functionalities in structures.

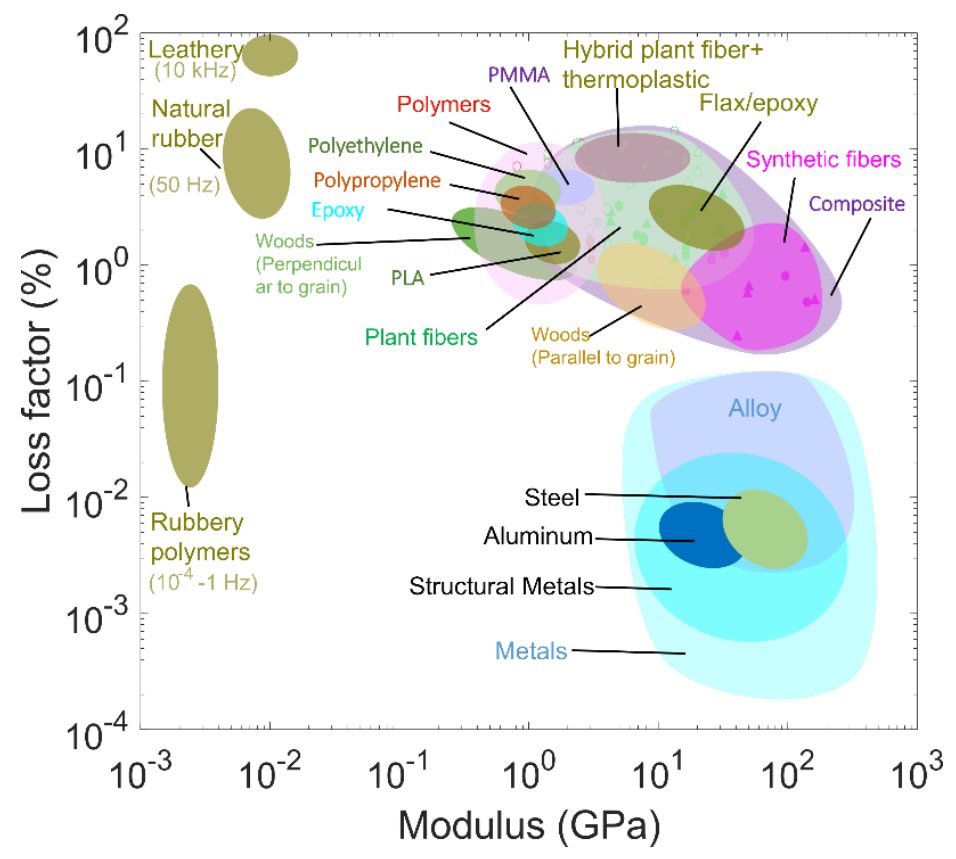

Figure. 2 Ashby diagram: loss factor vs. modulus (summarized from refs. [10,27-62], triangles are measured by modal tests at first mode (around $20-200 \mathrm{~Hz}$ ) and ambient temperature, circles are measured by DMA tests at $1 \mathrm{~Hz}$ and ambient temperature)

Indeed, literature clearly points out that the loss factor of PFCs is generally much higher than SFCs. PFCs have reported values of loss factors comprised between $0.7 \%$ and $14 \%$, while values are typically comprised between $0.24 \%$ and $2.5 \%$ for SFCs. Loss factor and storage modulus (or Young's modulus) at ambient temperature were collected from literature and plotted in a stiffness-loss map as proposed by Lakes et al. [51,63] for different material families (Figure 2). Due to their internal structures, metals exhibit high stiffness and low loss factors. On the opposite, the chemical composition of polymers 
results in low stiffness and relatively high loss factors. The combination of components in composite materials is currently the best way to provide compromises between stiffness and loss factor. In this category, PFCs globally perform better than SFCs in terms of damping.

The sources of energy dissipation in fiber reinforced polymer composites are quite well described and documented in literature [12,64-67]. They are mainly: (1) viscoelastic nature of the matrix and/or fiber materials, (2) damping due to interphase, (3) damping due to inelastic and irreversible behaviors such as damage and/or plasticity. By contrast, the damping behavior of PFCs, even if already documented [27,68] is not fully covered. Furthermore, various effects on damping are observed when plant fibers are introduced in polymer matrices depending on the nature of the polymer, stiffness, textile architecture and yarn lengths [27]. The physics underlying their particular behavior is not yet fully understood and require additional research efforts. Also, the length scales corresponding to all dissipation mechanisms that may occur in these multiscale materials can result in damping occurring at various time (or frequency) scales. Therefore, this paper aims at reviewing the current knowledge on the damping behavior of PFCs in order to draw the needs for the future research activities, and to evaluate their potentialities to reach specific levels of damping of composite materials. All over the paper, the term damping is used to describe the physical mechanisms corresponding to energy dissipation occurring when the materials are subjected to cyclic deformations, while the term loss factor refers to the ratio of the energy dissipated per cycle to the maximum strain energy stored in the 
material during the cycle, which is widely used to describe the damping performance of materials and structures.

In this paper, we propose to review the existing studies on the damping behavior of PFCs. The classical experimental techniques used to characterize the damping behavior of composite materials are first discussed in section 2. Section 3 proposes to review the studies available in the open literature. The analysis is performed using different key parameters owing to the mesoscale (including reinforcement type, stacking sequence), microscale (fiber, matrix, interface/interphase and porosities) and related to testing and environmental conditions (moisture and temperature). Section 4 discusses the current limitations in the existing studies. Finally, conclusions are given in section 5.

\section{On the experimental techniques for the characterization of composite damping}

In this section, the most widely used damping characterization techniques such as DMA tests, modal analyses and wave number-based approaches are briefly described.

\subsection{Quasi-static and low frequency characterization: DMA}

One of the most widely used non-resonance techniques for damping characterization is Dynamic Mechanical Analysis (DMA). It is usually used to characterize viscoelastic materials with low stiffness such as polymers, or organic composite materials, and is widely used for the rheological analysis of polymers and elastomers, especially in the fields of chemistry and materials science [69]. In particular, their glass transition 
temperatures can be identified through temperature sweep curves at different frequencies.

The storage modulus $\left(E^{\prime}\right)$, loss modulus $\left(E^{\prime \prime}\right)$ and loss factor $(\tan \delta)$, are usually identified from DMA tests to describe the viscoelastic properties of materials for various temperatures $[28,33,69-72]$. The temperature range of interest is generally investigated either through temperature ramps or temperature steps. In the latter case, isothermal conditions are used often with a temperature stabilized stage of several minutes to make sure that the sample has reached a homogeneous temperature distribution $[70,71,73]$. Harmonic excitation is usually set between $0.01 \mathrm{~Hz}$ and $100 \mathrm{~Hz}$ in most existing studies, since DMA apparatus always exhibit mechanical resonances in the higher frequency range, that affect the measurement [34,74-76]. In addition, another essential factor that needs to be considered in DMA is the ratio of the stiffness of the sample to that of the apparatus: the stiffness of the sample should be much smaller than the stiffness of the system to obtain accurate test results, especially for storage modulus [70]. Furthermore, the deformation of the sample should be kept in the linear viscoelastic range to meet the theoretical requirements [69]. Despite of these limitations in terms of frequency, DMA remains a popular technique for the characterization of damping, in particular because the Time-Temperature Superposition (TTS) principle, which is verified for a large set of polymers and composites, can be used to estimate their damping and stiffness properties in the higher frequency range $[69,70]$.

\subsection{Low to mid-frequency characterization: modal analysis}

Modal analysis is another common method for damping identification. Natural 
frequencies, damping ratios, and modal shapes of composite structures are estimated at resonances by using an external excitation source within a specific frequency range $[10,77,78]$. These methods are efficient on frequency ranges starting at the first eigenfrequency of the structure, up to mid-frequency range which is typically reached when the $-3 \mathrm{~dB}$ bandwidth of subsequent modes are superimposed one to another, hence depending not only on the materials, but also on the geometry and the boundary conditions. Several excitation signals and boundary conditions can be used for resonance testing. Existing techniques for damping measurement using logarithmic decrement decreasing free vibrations of beams are reported [60,78-82]. The test configuration is important: several aspects are discussed in the literature, such as the location of the excitation, boundary conditions, adhesion of the accelerometers, and interference of the measurement $[70,77,78,83,84]$. Specific techniques for composite structures are proposed for beams on complex shapes [85-88].

Since there is usually no heating or cooling device used in the modal analysis tests, the samples are sometimes placed in a constant temperature oven to maintain the required test temperature $[7,89]$. However, these settings can generally not be used to reach high temperatures because most instruments cannot tolerate excessive temperatures.

\subsection{High frequency characterization: wave number-based approaches}

Marchetti et al. review several wave number based approaches used for the characterization of the dynamic properties of composite structures in frequency ranges where modal analysis approaches become unpractical as the increased modal density is 
too large $[90,91]$. The loss factor and storage modulus can be computed from the natural wave number obtained from the high frequency analysis.

However, this type of characterization has not been widely applied for PFCs at this time, so this frequency range is not addressed in this review paper. The works by Zhang et al. and Duval et al. can be mentioned as first inputs to be completed in future researches with additional data related to damping properties of PFCs in high frequencies $[48,92]$.

\section{Review of studies on the damping behavior of PFCs}

\subsection{Mesoscale parameters}

This section discusses the effects of mesoscale parameters (features of laminate) on damping, given the issues of reinforcement architecture and stacking sequence.

\subsubsection{Reinforcement type}

Plant fibers can be processed into many kinds of reinforcements such as short fibers, nonwoven, non-crimp fabrics, and woven fabrics. It leads to composite meso-structures with significant differences. This part summarizes the effect of different kinds of reinforcement types on damping performances.

For short fiber composites, Senthil Kumar et al. [93] investigated the influence of fiber length and weight percentage on the free vibration characteristics. Their study concerned banana fiber and sisal fiber polyester composites. Results show that the fiber content influences more the free vibration behavior that the fiber length. This is attributed to the shear behavior at the fiber ends. The authors also claim that the damping of banana 
fiber is higher than that of sisal fiber owing to the smaller diameter of banana fiber and a thicker interface could appear, as reported by Bledzki et al [94].

Sreenivasan et al. reported that for Sansevieria cylindrica fiber reinforced polyester matrix composites the dynamic characteristics are significantly influenced by the increase in fiber length and fiber loading but not in a geometric progression [35] In contrast, the loss factor of short synthetic fiber composites are found higher than that of long fiber composites, due to the long fibers that limit the movement of polymer molecules [95-97]. The fiber-matrix interface is considered as a significant source of energy dissipation of discontinuous synthetic fiber based composites since short fiber increase more fiber ends and fiber-matrix interfaces [95]. However, the comparisons of discontinuous, short and long plant fiber composites under the same condition are rarely reported.

When woven reinforcements are considered, most of the authors report a reduction of damping level compared to unidirectional reinforcements (UD) in transverse direction such as tapes $[27,47,98-100]$. Among the different weave patterns investigated, the loss factor in huckaback-type woven composites is found to be higher than that of plain, satin, twill, and basket because their performances depend on the interlace between the warp and weft directions, which increases the interaction between fiber and matrix [101]. Also, twisted yarns generally induce decrease Young's modulus because of the induced crimp but increase the damping through enhanced inter-yarn friction [102].

However, the existing reports have not found any significant effect of long fibers on damping when compared to short fibers and continuous reinforcements $[32,48]$. Some 
research efforts focused on the comparison of the effects of these three types of reinforcement on damping performance are still required.

\subsubsection{Stacking sequence}

The effect on damping of different stacking sequences, using some common arrangements such as $0^{\circ}, 45^{\circ}$, and $90^{\circ}$ are investigated by several authors. When it comes to symmetric layups, composites often show lower damping level in longitudinal direction when $90^{\circ}$ at the outer layer and the highest for that when $0^{\circ}$ at the outer layer [103]. The authors indicate that this is related to the flexural properties of the composite structure. In particular, the shearing effect is found to enhance resistance to fiber mobility and increase the effective load transfer between fiber and matrix in turn [104].

Stacking sequences with long UD fibers and randomly oriented short fibers are also studied. Results show the stacking sequence does not influence the dynamic mechanical properties (including storage modulus, loss factor) of the studied PFCs in longitudinal direction [105].

Some research on hybrid fibers (flax and E-glass fibers woven fabric) show that the best damping performance are obtained in longitudinal direction when flax fibers are distributed in the outer layer [47]. Y. Li et al. find the damping properties in hybrid composites (flax and carbon fiber) are greatly influenced by the position of the flax fiber layers, which are supposed to dissipate more energy than those with synthetic fibers in fiber direction [45]. Contrary results have also been reported in the latest literature [106] for hybrid composites made of basalt and flax woven fabrics ( $0 / 90$ orientation). Authors 
observed that the maximum damping is obtained when basalt is in the outer layer $[106,107]$.

\subsection{Microscale parameters}

This section discusses the effect of microscale parameters on damping, such as fiber type, fiber orientation, fiber volume fraction and microstructure. Meanwhile, treatments of fiber, interface between fiber and matrix, and porosities are also discussed.

\subsubsection{Fiber}

\subsubsection{Fiber type}

This section summarizes the damping characteristics of composites with different types of fibers.
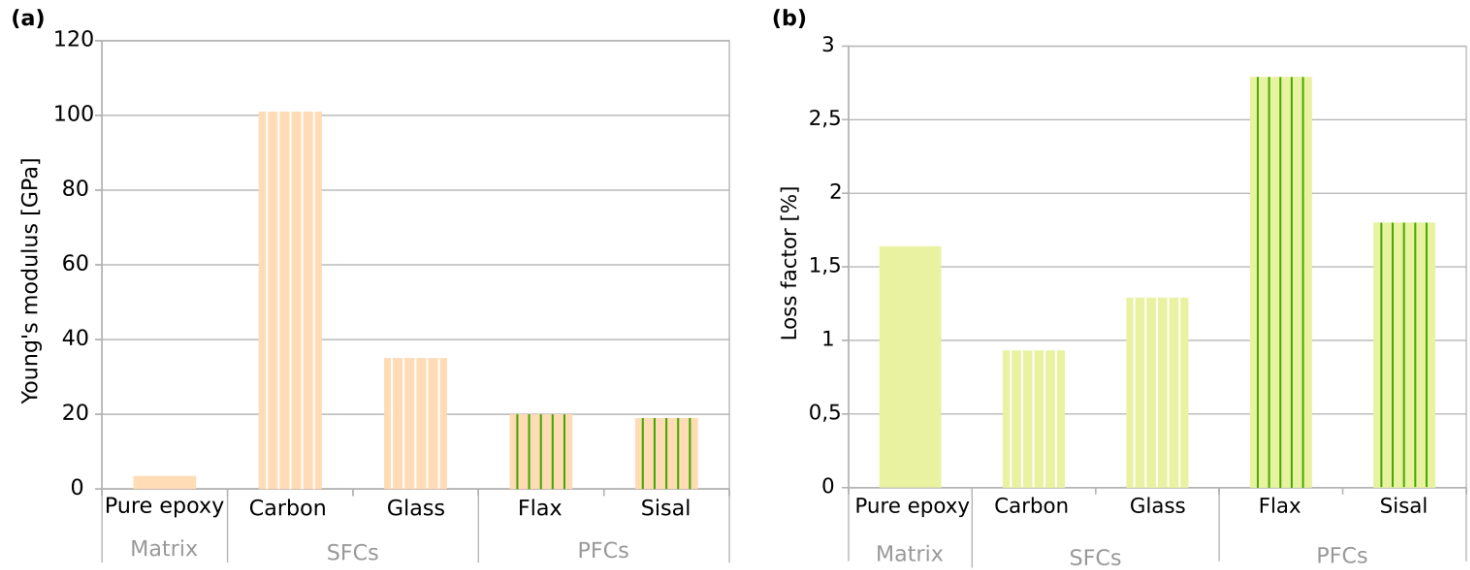

Figure. 3 (a) Young's modulus and (b) loss factor of unidirectional (UD) fiber reinforced epoxy composites in the longitudinal direction (measured by DMA tests at 1 $\mathrm{Hz}$ and ambient temperature), summarized from refs. [27,31,33]

Figure. 3 proposes a synthesis of the loss factor and Young's modulus values 
collected in literature for epoxy matrix with different unidirectional reinforcements made from different types of plant and synthetic fibers. The presented results are collected using DMA tests at $1 \mathrm{~Hz}$ and ambient temperature.

As expected, the Young's modulus of the composites in the longitudinal direction is significantly higher than the one of the neat epoxy. The stiffening factor varies as a function of the fiber type. For the considered results in Figure 3 (a), it is approximately 25 times with carbon fibers, 8 times with glass fibers and at least 5 times with flax fibers, compared with neat epoxy.

It can also be observed that the fiber type does have a significant effect on the damping properties (fiber volume fraction can also be a factor, but most authors have not stated it in the literature). The addition of synthetic fibers into epoxy induces a decrease of the damping in the longitudinal direction. For the considered results in Figure 3 (b), it is approximately decreasing of $40 \%$ and $20 \%$ with carbon fibers and glass fibers, respectively, compared with neat epoxy. This is attributed to stress transfers from the matrix to the fibers and by the fact that the presence of stiff fibers limits the chain mobility in the in the matrix, which implies that the friction of the intermolecular chain is reduced $[49,108,109]$. Conversely, the addition of plant fibers increases damping. It is approximately increasing of $70 \%$ with flax fibers as it can be seen in Figure 3 (b). This is attributed to the friction at the interface but also may be due to the intrinsic damping capacity of the fibers themselves $[27,68,102]$. However, the damping is also sometimes reported decreased in flax/epoxy composites [50] compared with that of pure epoxy [27] 
but this comparison may ignore the impact of different test methods. Figure 3 also points out that the loss factor obtained with flax fibers is high than with sisal. Anyway, more tests including a large variety of fibers in the form of continuous UD reinforcement and with a same matrix and similar volume fractions are recommended in order to better evaluate the influence of the fiber type on the damping of their composites.

It was also shown by Hadiji et al. that nonwoven composites reinforced by plant fibers present higher loss factors compared with those of glass-based composites [149]. The loss factors of polypropylene composites based on non-woven hemp, flax and kenaf reinforcements are 2 to 25 times higher than glass-PP composites. Among the tested plant fibers, it can be observed that the higher damping is obtained with hemp and flax.

In addition, some authors also show that the incorporation of ramie fiber in epoxy tends to increase the damping due to weak adhesion which indicates low interfacial shear stress [28]. Another reason that may explain the diverse damping with these plant fibers is the difference in inherent morphology of fiber surface [93].

Hybrid plant fiber composites are also reported regarding damping performance. Results show that hybrid plant fiber composites with banana/coconut sheath or kenaf/bamboo possess higher loss factors compared to single fiber composites [112]. Hybrid fibers combine the advantages of their components and achieve superior performances that cannot be obtained from only one type and authors also claim damping values are higher for all hybrid composites possibly due to greater energy dissipation and restricted molecular mobility at the interface [113-115]. 


\subsubsection{Fiber microstructure}

Plant fibers differentiate from the conventional ones in terms of composition, and microstructure. Indeed, plant fibers often have unique microstructures and morphologies, notably different cell wall layers and a complex cross-sectional area which varies along the fiber length [116-119]. In additional to this complex morphology, plant fibers have also a polymer-based composition and a very hierarchical organization with different layers and sublayers made of a mixture of carbohydrates and polyphenols [120,121]. It imparts them viscoelastic properties [122-126]. These particularities lead also to specific static and fatigue behavior which were quite widely studied in literature, including nonlinearities [127,128], stiffening effects [129] and moisture activation of some mechanisms [130-132].

It could also be at the origin of specific energy dissipation mechanisms and particular damping behavior. Only few studies investigate the damping behavior of plant fibers [133-136] and, unfortunately, the influence of the fiber microstructure on the damping of the PFCs themselves has not been studied so far.

PFCs are made of single individual fibers but also bundle of fibers. Friction at the interface between individual fibers within the fiber bundle, internal friction within fiber wall (between the heterogeneous polymers constituting the wall and particularly between the rigid cellulose microfibrils and the amorphous polymers in which they are embedded) $[27,68,102]$ are also potential sources of damping. Additionally, plant fibers have a finite length when compared with synthetic fibers. The effect of such discontinuities, even for 
continuous reinforcement, on the damping behavior of PFCs can be questioned and deserves to be investigated in the future.

\subsubsection{Treatments}

Several investigations on the effect of pre-treatments on the plant fibers to achieve better mechanical performances in PFCs have been reported. This section summarizes the treatment methods and their effects on composite damping, including functionalization using nanotubes, chemical treatments, etc. which may change the interface state.

Carbon nanotubes (CNTs) are proposed to enhance the damping property of PFCs and SFCs [137]. Damping is further enhanced by the stick-slip action of CNTs that takes place at the CNTs/matrix interfaces. Besides, the penetrated CNTs interact with microfibrils in the S2 cell wall of plant fibers, leading to effective stress transfer from matrix to microfibrils, which contributes to energy dissipation and enhancement of damping property [45]. In contrast, some authors also claim the presence of stiff fibers limits the chain mobility in the matrix, which implies that the friction of the intermolecular chain is reduced $[49,108,109]$.

Other results report the effect of microfibers. The addition of macro/microfibers decreases the damping characteristics of PFCs and increased storage modulus, as the added fibers act as barriers to the free movement of the macromolecular chains. As a contrast, the unfilled matrix has the highest damping ratio, indicating a significant degree of mobility [138]. 
It demonstrated that the improved interaction exerted by the chemical treatments makes the PFCs and SFCs more compatible and with better adhesion than the untreated fiber composites $[139,140]$. Moreover, some authors claim that a high-quality interface tends to lower energy dissipation, showing a lower value of the damping peak $[141,142]$. The effect of chemical treatments such as acid, alkali, ethanol, and silane agents are studied. Chemical modifications cause the hemicellulose removal, which increases the number of hydrogen bonds between the modified fibers and the matrix [143]. The alkali and potassium permanganate treatment of PFCs leads to higher damping when compared to other earlier reports $[41,144]$. The authors explain that the damping characteristics of heterogeneous systems is not only based on interfacial bonding but also depends on different parameters like change in interfacial thickness, bending of fibers, broken fibers, matrix cracking and formation of cavities due to the fiber pullout [47].

Different chemical reaction times show not much difference in the height of the loss factor's peak [32]. Some authors claim that the reduction of the amplitude of the loss factor's peaks means well-combined load capacity, due to a good stress transfer between interface [30,37]. Silane-treated fiber composites lead to better fiber/matrix interactions than other treatments $[145,146]$. Alkali and silane treated surfaces are rough, which are formed by the elimination of lignin and hemicellulose compounds. A rough surface enhances fiber/matrix adhesion and increases both the glass transition temperature and loss factor during glassy state $[145,147]$. This can be also explained as the combination of the shear stress concentration at the fiber end and the additional viscoelastic energy 
dissipated in the matrix material $[146,148,149]$.

Besides, Yadav \& Gupta find fiber coating (PLA+ Chloroform) followed by chemical treatments can improve the damping at ambient temperature, and could also be considered as a practical approach to improve the performance of composite materials for advanced applications [150].

In general, the effect caused by treatment on composite damping is based on the changes of the fiber/matrix interface. The quality of the interface determines the change in damping, but sometimes there are still conflicting conclusions.

\subsubsection{Fiber volume fraction}

PFCs with a single type of reinforcement in the form of short fibers are studied to investigate the influence of the fiber volume fraction on damping properties. Sathishkumar et al. showed that the damping, measured using free vibration technique, increases with the fiber content (up to $50 \mathrm{wt} \%$ ) for sisal, while it decreases for banana fiber composites [93]. This result is attributed to the difference in inherent morphology of fiber surface [93]. Etaati et al. also investigated the influence of the fiber volume fraction on the damping behavior of short hemp fibers reinforced polypropylene composites [42]. They reported that composite with $30 \mathrm{wt} \%$ noil hemp fiber shows the highest damping capacity among all investigated composites, for fiber volume fractions comprised between 0 and $60 \%$. Tajvidi et al. indicated that the presence of higher fiber contents can considerably reduce damping, indicating that the composite material is more elastic at higher fiber contents [151]. The interface area increases with the number of 
incorporated fibers, which leads to stronger interactions. Therefore, the molecular mobility of the polymer decreases and the mechanical loss that overcome intermolecular chain friction is reduced [152]. As previously mentioned, other reports show the dynamic characteristics are significantly influenced by the increase in fiber length and fiber loading by the changes of interface but not in a geometric progression, as in the case Sansevieria cylindrica fiber reinforced polyester matrix composites [35].

For non-woven composites, the loss factor of flax/PP composites is observed to decrease of approximately $20 \%$ when increasing the flax weight ratio from 30 to $70 \%$. This is attributed to the superior contribution of PP on damping [110].

Increasing the fraction of synthetic fibers in hybrid fiber composites (flax and carbon fiber) reduces damping [58], but there are also reports of increase damping [153], without clear physical explanation of this observation.

In summary, the impact of fiber content on damping often presents conflicting conclusions in the existing literature considering the different types of fibers used and their architecture. Therefore, dedicated experimental studies as well as modelling approaches need to be established to explain these inconsistent conclusions in future research.

\subsubsection{Fiber orientation}

Different fiber orientations can be used during the design of composite laminates and structures. Damping performance of PFCs with different fiber orientations has been 
studied in the past decades.

The loss factor of flax/GreenPoxy 56 (GP56) composites are tested from $0^{\circ}$ to $90^{\circ}$ fiber orientation using a modal method [154]. Results show that the loss factor decreases as the frequency increases. This is attributed to the high internal friction between cellulose and hemicellulose caused by the flax fibers microstructure, especially at low frequency $[27,50,59,154]$. A maximum loss factor is always found at $70^{\circ}-75^{\circ}$ fiber orientation for different frequencies.

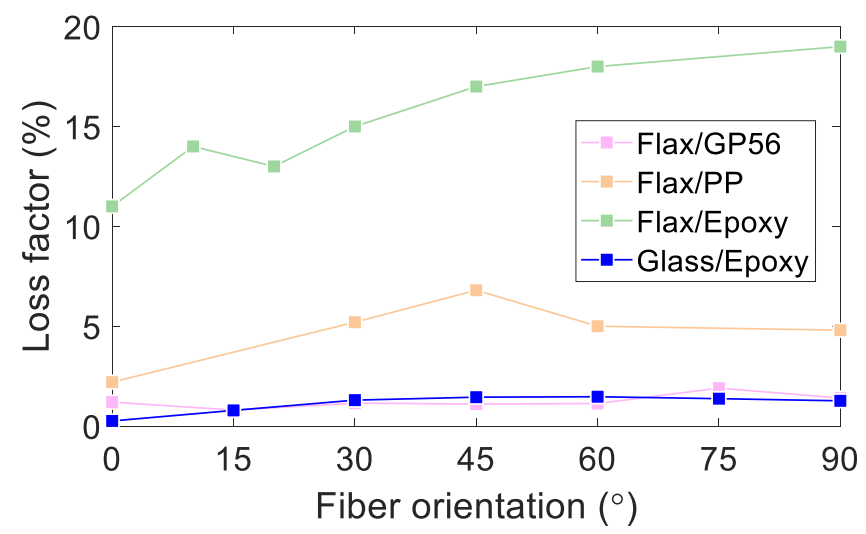

Figure. 4 Variation of loss factor as function of fiber orientation in UD composites in longitudinal direction using modal tests (a) Flax/GP56 [38], (b) Flax/PP [155], (c) Flax/Epoxy [60], (d) Glass/Epoxy [156]

In other reports, the loss factor is found to increase at first, and then to decrease with the increasing fiber angles in flax fiber-reinforced polypropylene (PP) [155]. Some authors show that the maximum loss factor is obtained around $45^{\circ}$ fiber orientation, which is similar to glass fiber composites and carbon fiber composites [156-158]. This phenomenon is attributed to the in-plane shear strain energy of fiber-reinforced 
composites which is the maximum at this fiber orientation [109]. However, the global trend is that the loss factor of the fiber orientation in $90^{\circ}$ is higher than that of $0^{\circ}$, as shown in Figure 4, in which (a) and (b) are measured around $500 \mathrm{~Hz}$, (c) is obtained around 300$400 \mathrm{~Hz}$ and (d) is measured around $300 \mathrm{~Hz}$.

Unlike the unidirectional PFCs, loss factor varies slightly from the longitudinal direction $\left(0^{\circ}\right)$ to the cross direction $\left(90^{\circ}\right)$ in nonwoven PFCs [110]. Indeed, the anisotropy level is less pronounced than in UD composites

It should be emphasized that testing UD composites out of longitudinal and tangential directions requires strong attention on the experimental setup in order to guarantee the homogeneity of the strain and stress fields in the sample. Moreover, the identified properties correspond to coupled information between the material properties corresponding to the principal directions. For this reason, it may be preferable to focus only on the principal directions when using DMA-like tests, or use free-free vibration tests that are not affected by out-of-axis boundary conditions. Additionally, purely UD panels are rarely used in practical applications where cross ply composites are preferred, whose properties can be identified from longitudinal and tangential data.

\subsubsection{Matrix}

This section summarizes some research results on the dynamic mechanical properties of conventional polymers and their PFCs. 


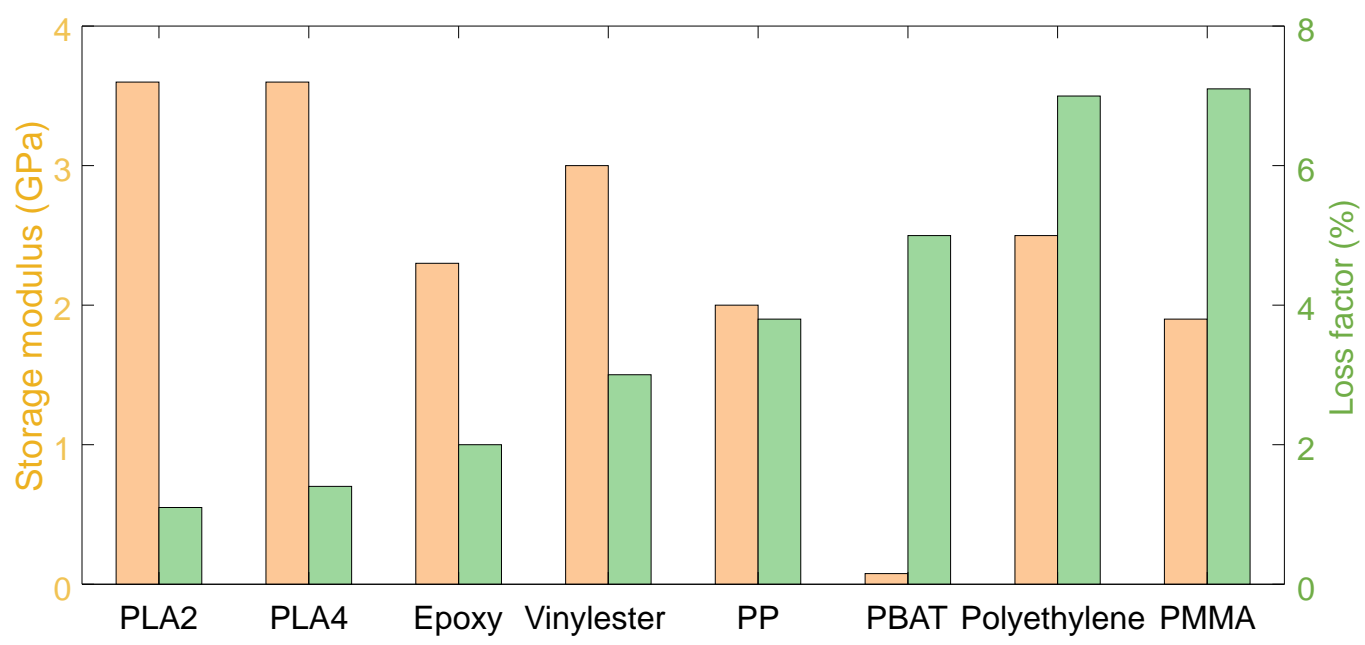

Figure. 5 Loss factor and storage modulus of different polymers at $1 \mathrm{~Hz}$ and ambient temperature summarized from [27,28,36,39,61,71,159] (Polylactic acid 2, 4 (PLA 2, 4), and Polypropylene (PP), Polybutylene adipate-co-terephthalate (PBAT), Polymethyl methacrylate (PMMA))

Figure 5 summaries some dynamic mechanical properties of pure matrices, which are widely used in industrial production. Thermoset polymers, such as epoxy, are the most widely used matrix for PFCs and SFCs due to the excellent adhesion of resin and the long lifecycle. However, thermoset polymers tend to be more brittle and less tough than thermoplastics [1]. The reason is that high loss factor values are associated with ease of movement of side chains, functional groups, segments, pendant groups, and even entire molecules in the polymer. Moreover, the loss factor is reduced by the presence of negatively charged atoms (such as oxygen and nitrogen) in the molecules, which reduces the motion of hydrogen bonding [160]. This phenomenon is also interpreted as a mechanism for damping in polymer blends provided by network and interfaces [161]. Although thermoplastic polymers exhibit higher energy dissipation than thermosets, 
thermosets are often preferred due to their higher stiffness and better adhesion properties $[1,162]$.

Besides, results with particle additions are also reported. The mixture of agar particles restricts the mobility of the chains, and this performance reduces the sharpness and the maximum value of loss factor. The viscosity is substantially enhanced by fillers at a low shear rate, and in this case, the rheological behavior is utterly dependent on the composition of the polymer in the interfacial region [57]. It is also reported that the incorporation of solid fillers into the polymer matrix could increase or decrease the damping of the polymer, depending on the quality of fiber-matrix bonding $[32,76,163,164]$. Also, it can be observed that the damping factor decreases with the increase in bio-filler contents because the rigid particles restrain the mobility of the polymer molecules, raise the storage modulus, and reduce the loss factor [165].
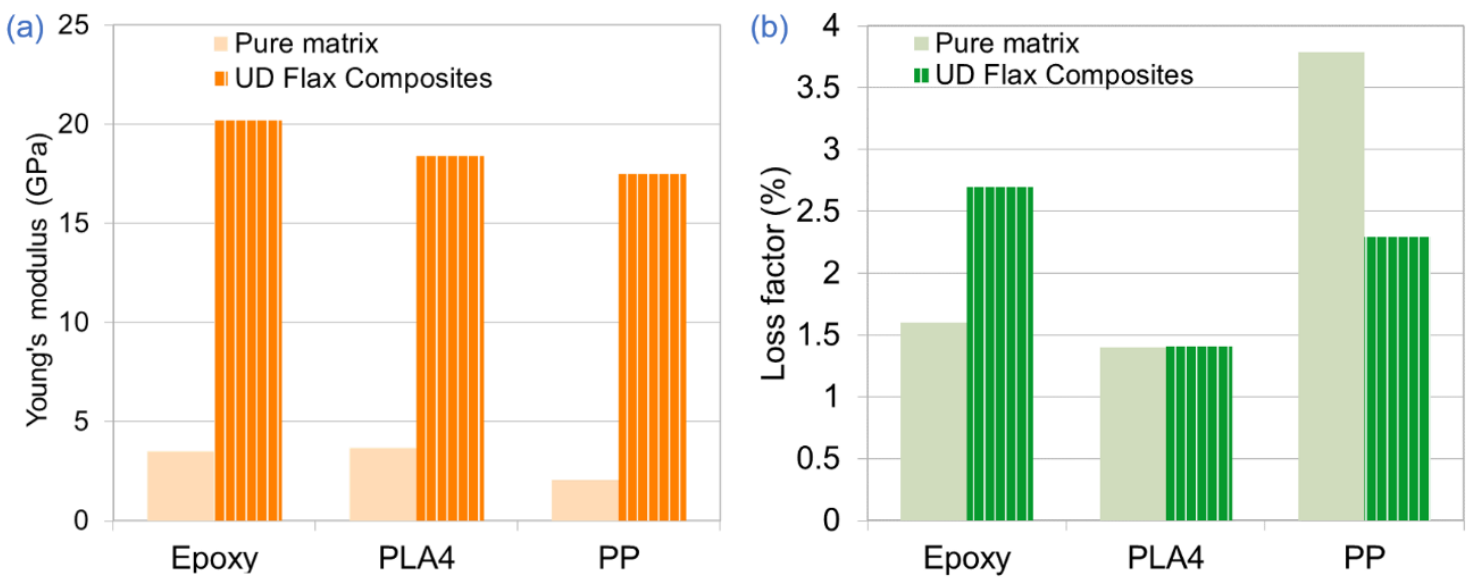

Figure. 6 Young's modulus (a) and loss factor (b) of flax composites in the longitudinal direction and pure matrix measured by DMA at $1 \mathrm{~Hz}$ and ambient temperature (summarized from ref. [27]) 
The Young's modulus and loss factor of the more widespread thermoset (epoxy), thermoplastic (Polylactic acid 4 (PLA 4), and Polypropylene (PP)) polymers used for flax composites are reported in Figure 6 [27], for both pure resin and UD flax composites. Although the reinforcement is the same, their global damping is quite different. The addition of plant fiber in epoxy, PLA4, and PP show a distinctly different trend in loss factor, but a total increase in modulus. This is because of the interactions between fiber and matrix, and aspect discussed in the following section. It could also depends on the contribution of the internal friction in the fibers to the overall damping response [27].

\subsubsection{Interface / interphase}

As abovementioned, interfaces play a critical role in the damping properties of composites. Their properties depend not only on the manufacturing process but also on the treatments, which have been discussed in the fiber treatment section, as shown in Figure 7. This section focuses on the original interface.

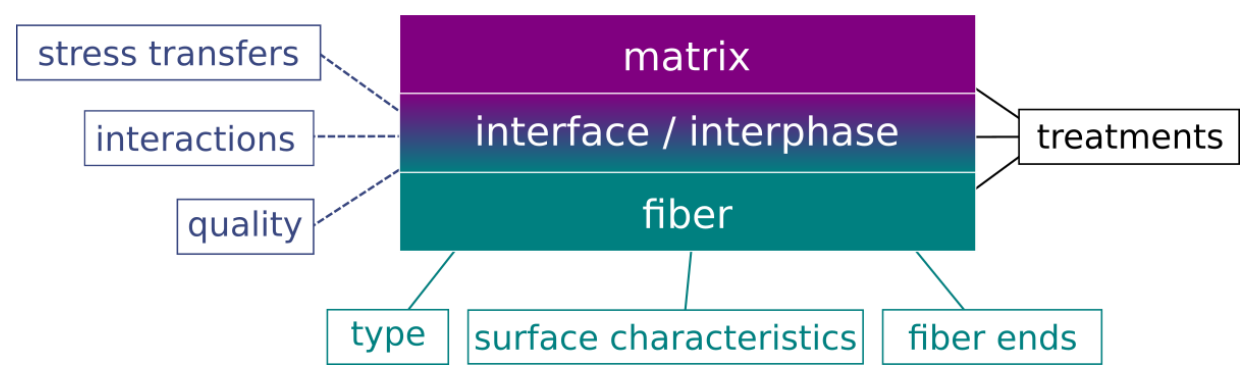

Figure. 7 Parameters related to the interface properties

It is reported that a composite with weak interface bonding tends to dissipate more energy than that with good interface bonding $[49,166]$. However, other reports show that an increased damping can be obtained often by improvement of fiber/matrix adhesion, 
which may activate the damping phenomena such as intra-cell wall friction between the cellulose microfibrils and the hemicellulose/lignin matrix in each cell wall and inter-cell wall friction between the cell walls [102].

In most cases, higher resin contents for most organic-based composites should lead to higher damping due to its viscoelastic properties. However, in some cases, the reduction of the matrix fraction increases the damping. This is due to the interface thickness and interface stiffness that also play an essential role in the damping mechanisms [12].

It was previously reported that the incorporation of stiff fibers affects the damping behavior of matrices by changing the movement of polymer chains [96,167-169]. With certain thermoset systems, the proximity of the stiff fibers and preferential adsorption and/or absorption of diffusible constituents, in particular low molecular weight curatives, on the fiber surface or in the fiber wall may impose a relatively high crosslink density, decreasing locally the damping behavior of the resin. At the same time, this may lead to some softening of the matrix in the zone next to the interface because of the depletion of the curative [167]. This is particularly conceivable with plant fibers, which have a certain affinity and/or absorption ability with the curatives. Plant fiber reinforcements are also generally made up of yarns of elementary fibers. The friction mechanisms between fibers (intra-yarn friction) as well as the friction between the yarns (inter-yarn friction) could increase the intrinsic damping with respect to that obtained with synthetic fibers [27].

Some studies show that the loss factor and stiffness of interleaf films play an 
essential role in the loss factor of the interleaved laminates at the test temperature [170].

\subsubsection{Porosities}

Porosity is inevitable during the manufacture of composite materials, in particular with plant fibers. However, its influence on the damping behavior of PFCs is poorly discussed in literature. A report on hybrid fiber composites (SFCs+PFCs) describes the effect of the existence of voids on damping characteristics. The damping is found to be not sensitive to the void content. This might be due to the small void content in the samples reducing the contribution [47]. For non-woven PP composites, a recent study by Hadiji et al shows that the loss factor increases by $108.7 \%$ when the porosity changes from 9 to $64 \%$ based on modal analysis [110]. This is attributed to poor adhesion between fiber and matrix leading to more energy dissipation $[110,171]$.

Additional research on this topic regarding different types of PFCs, such as woven pattern, matrix (thermoset or thermoplastic), etc., is necessary since not enough conclusions have been reached at this time.

\subsection{Testing and surrounding conditions}

\subsubsection{Testing technique and frequency-dependent}

The testing techniques may have an influence on the determined values of the loss factors [89]. So, the damping results from DMA tests and modal analysis tests are compared in some studies [60,70,89]. Regarding PFCs, Rueppel et al. describe damping measurement tests with three different strategies: DMA, logarithmic decrement 
measurement method (LDM) and vibration beam measurements (VBM) [60]. The values obtained from DMA and VBM have a significant difference, which is attributed to air resistance effects as the amplitude of vibration is larger during VBM [60,172]. LDM provides non-linear decay for the materials and the authors recommend to carefully consider initial parts of the displacement curve during tests, especially for high damping materials. It is then essential to take into account the experimental techniques when comparing damping properties of different materials.

The damping properties may vary as the changes of frequency. The loss factor of UD or twill flax fabric reinforced epoxy composites are observed decreasing trend for low frequencies $(<500 \mathrm{~Hz})$ and then stabilization for higher frequencies $(500-2000 \mathrm{~Hz})$ $[38,59,154,173]$. Assarar and Daoud explain that the vibration behavior at low frequencies is result from the internal friction between cellulose and hemicellulose in the plant fiber and this kind of friction is more pronounced at low frequencies $[27,38,59]$. However, UD flax reinforced polypropylene or epoxy composites are observed an slight increasing trend at low frequencies $(<1000 \mathrm{~Hz})[50,155,174]$. In addition, the damping properties of UD flax/PA11 composites were also obtained over a large frequency range $(2000-10000 \mathrm{~Hz})$ and it was difficult to derive a trend due to the coupling of the plate vibration with aerodynamic phenomena [43]. Therefore, an experimental technique that can eliminate the influence of air and show the contribution of each component (fiber, matrix and interface) on damping properties as a function of frequency is proposed in the future. 


\subsubsection{Environmental conditions}

Researchers have also paid attention to the influence of some external factors in addition to the inherent factors of PFCs components. In this section, the effects of external environment such as water aging or moisture content, temperature and various coupling conditions is summarized.

\subsubsection{Moisture}

The environment in which PFC materials are serviced is sometimes harsh, and in most cases, the environment is accompanied by changes in moisture content.

Plant fibers are sensitive to moisture temperature due to the hydrophilicity of some of their wall constituents and also due to their hollow morphology [175-178]. Therefore, their hygroscopic properties and effects need to be studied if plant fiber composite materials are to be used in engineering fields. Many factors affect water absorption characteristics in PFCs. External factors such as temperature, manufacturing features such as fiber fraction, fiber orientation, size and percentage of voids, interface factors such as exposed area, surface treatment, component hydrophilicity, and bonding quality of interfaces between fiber-matrix are proved to be critical influencing factors [179-181].

Generally, the absorption of water in PFCs is started by water entering the plant fiber through capillary transport. Materials with micro-crack defects also accelerate the diffusion of water. Plant fibers absorb water and cause the fibers to swell, leading to micro-cracks in the fiber-matrix interface area $[182,183]$. Moreover, this diffusion is 
enhanced by the aging of the material itself [181], which causes the deformation and mechanical properties of the PFCs to decline $[184,185]$. Many studies have shown that good interfacial properties between fiber reinforcement and matrix or better moisture absorption resistance can reduce the effect of moisture absorption on plant fiber [184].
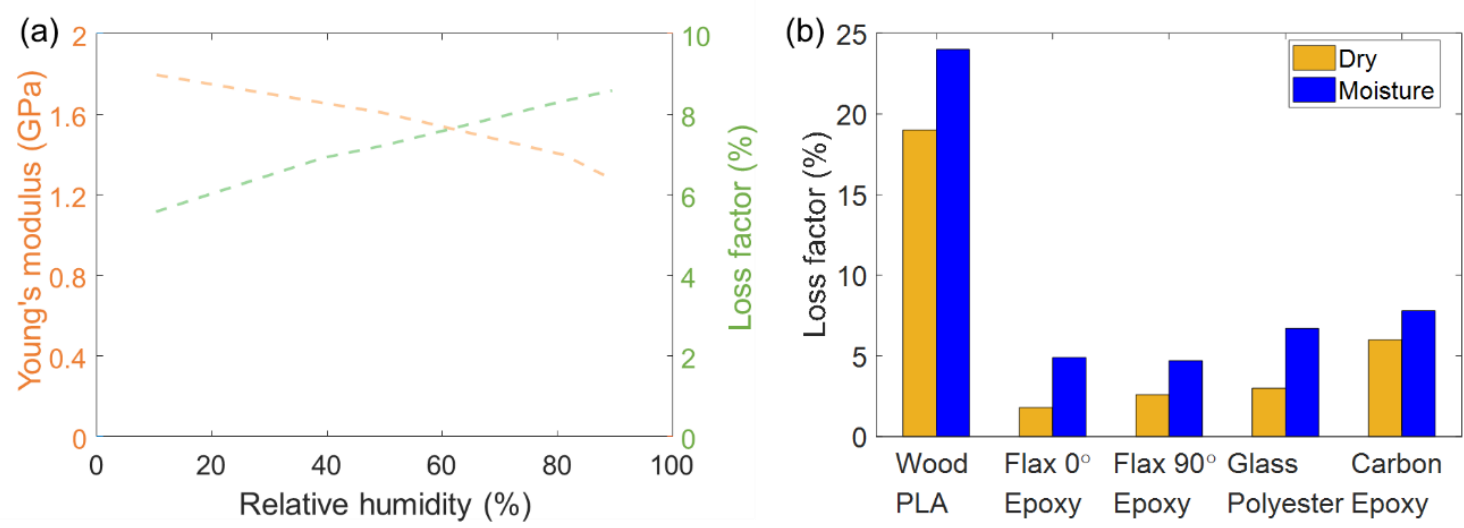

Figure. 8 Young's modulus and loss factor of (a) wood fiber composite and (b) different kinds of composites based on DMA tests at $1 \mathrm{~Hz}$ and ambient temperature with respect to relative humidity and after water absorption (summarized from ref. $[173,186,187]$ )

Damping is generally observed increasing with the increasing relative humidity in PFCs at the expense of Young's modulus. Damping of wood fiber composite is more sensitive to relative humidity than Young's modulus, changing by $26 \%$ and $-13 \%$ from dry to humid conditions, respectively, as shown in Figure 8 (a) [186]. Berges et al. indicate a $50 \%$ increasing of damping ratio after water vapor saturation of flaxtape/epoxy composites [188]. Reports on synthetic fiber composites are also available, but the effect of relative humidity on stiffness is not significant [130,131]. In addition, the matrix of a composite material usually exhibits plasticization and swelling when exposed to moisture. 
Damping is very sensitive to changes in stiffness of the outer layer due to the plasticization of macromolecular networks, which exacerbates energy dissipation [189]. In addition, the moisture present in the areas at the interfaces increases friction losses [131].

PFCs are not only affected by the matrix when dealing with wet environment compared to SFCs, but the changes in fiber molecules also need to be understood. The dynamic FT-IR technique can be used since the traditional macro-mechanical tests cannot provide information about the stress transfer between the fiber and the matrix [190]. As moisture is transported from the plant fibers to the interface between fiber and matrix, the ability to transfer stress between the fibers and the matrix is reduced [190]. The matrix bears more loads, and the in-phase contribution of the matrix increases relatively to that of cellulose [190]. The energy dissipation is related to the strain energy of the fiber and the friction between the different components is increased as water absorption [132].

The effect of fiber orientation changes have also been studied in UD composites. The sensitivity of damping in different fiber orientations to the moisture decreases gradually from $0^{\circ}, 90^{\circ}$ to $45^{\circ}$ [173]. The PFCs laminates with $90^{\circ}$ outer layers are profoundly affected by moisture meaning more sensitive effect on damping [131]. Therefore, this situation should be avoided in the design of composite materials if it is intended to be used in high humidity environments. However, another reason to explain the effect of stacking sequences, is that different fiber orientations have a different amount of water absorption before the specimen reaches saturation, which are not taken into 
account when discussing the effect on damping. Similar research is also reported in synthetic fiber composites [131]. In this work, a dehydrated flax composites specimen after water absorption is compared with the original specimen. Although a $15 \%$ decrease in the bending modulus is observed, the author claim that the damping performance is reversible because the damping in PFCs was mainly driven by the water content in the fiber and fiber friction. The effects of cracks and interface failures are found to be negligible [173]. Several authors claim that this behavior appears to be unrecoverable in glass fiber reinforced polymer composites because the damping of SFCs is mainly determined by the damping of the matrix and the interface $[12,187]$.

Damping performance under seawater or strong acids are also studied in addition to freshwater or pure water environments [62]. Research shows that plant fibers are more susceptible to acids than synthetic fibers [191]. Besides, a silane agent is proved to decrease the water absorption, which is caused by reducing the chance of hydrogen bonding between free -OH groups in cellulose and water molecules [145]. V. Fiore et al. also claim that $\mathrm{NaHCO}_{3}$ treatment show beneficial effect on damping properties of flax composites but not jute composites during exposition to salt-fog environments which is strictly related to the fiber's chemical composition [192].

In general, many reports on the effects of moisture on SFCs behavior are available, while researches related to PFCs have focused more on monotonic mechanical behavior. The effect of water-heat coupling on the damping using different types of PFCs needs more research. 


\subsubsection{Temperature}

The dynamic mechanical properties of organic-based composites are also strongly sensitive to temperature. Temperature is the first factor that affects damping properties in various external environments [193].

Below the glass transition temperature, the loss factor increases with temperature attributed to matrix softening [95]. The free volume and space of the molecule's internal movement increase when the temperature rises, which causes the storage modulus and loss modulus to decrease. An ideal damping material should have a wider transition region and higher peaks in loss factor. However, as the matrix of composite materials, the stiffness decreases significantly in the transition zone, which requires engineers to find a suitable compromise between stiffness and damping.

Besides, damping performances are strongly related to glass transition temperature $\left(T_{g}\right)$. The incorporation of plant fibers in the matrix generally induces a shift of $T_{g}$ toward higher temperatures and a reduction of the loss factor peak due to the restriction of the movements of the matrix chains. This suggests an increase in stiffness of the fiber-matrix interfacial zone, however, contradictory effects have sometimes been observed $[32,36,37,194-196]$. It strongly depends on the matrix type, its affinity with plant fiber and the resulting stiffness properties at the interface between fibers and matrices.

Besides, some results report the damping properties of flax/epoxy composites during thermal shock cycling conditions from $-40{ }^{\circ} \mathrm{C}$ to $28^{\circ} \mathrm{C}$ [197]. The maximum decrease in the loss factor observed is $8 \%$. In addition, it is reduced by about $50 \%$ for storage modulus, 
and dynamic mechanical properties reach an equilibrium state due to microdamage saturation after 100 thermal shock cycles. The glass transition temperature $\left(T_{g}\right)$ is not affected by the thermal shock cycling conditions.

However, most of the results available up to now provide a combine effect, temperature increase and specimen drying since it is really difficult using traditional experimental methods (such as DMA tests) to maintain the moisture content equilibrium within PFCs samples while changing the temperature. Hence, more researches are suggested in the future efforts to decorrelate the effect of temperature and moisture content.

Table 1 Main features in mesoscale, microscale and surrounding condition parameters

\begin{tabular}{lll}
\hline Parameters & \multicolumn{1}{c}{ Damping root } & Reference \\
\hline Fiber length & \multicolumn{1}{c}{$\begin{array}{l}\text { The ratio of fiber length to diameter, surface } \\
\text { contact area }\end{array}$} & {$[93-97]$} \\
\hline Weave patterns & Interlace between the warp and weft directions & {$[27,47,98-102]$} \\
\hline Stacking sequence & Shearing effect, effective load transfer & {$[45,104,106,107]$} \\
\hline \multicolumn{3}{c}{ Microscale parameters } \\
\hline Fiber type & $\begin{array}{l}\text { Stress transfers, intrinsic damping capacity of } \\
\text { plant fiber }\end{array}$ & {$[49,108,109]$,} \\
\hline Fiber orientation & In-plane shear strain energy & {$[27,68,102]$} \\
\hline Fiber volume fraction & Increase interface or restrict the mobility of matrix & {$[93,152]$} \\
\hline Treatments & Stress transfer, quality of interface & {$[45,141,142]$} \\
\hline Matrix & Molecular structure, interactions at the interfaces & {$[27,160,161]$} \\
\hline Interface & Fiber/matrix adhesion & {$[49,166]$} \\
\hline Porosities & Not enough study in porosities & - \\
\hline \multicolumn{1}{c}{ Surrounding conditions } & \\
\hline Moisture effect & Friction losses caused by interface damage & {$[131,145,182,183]$} \\
\hline Temperature & $\begin{array}{l}\text { Internal movement of molecule chain, changes in } \\
\text { microstructure of plant fiber }\end{array}$ & {$[95,197]$} \\
\hline
\end{tabular}

In this section, the effect from mesoscale parameters (reinforcement type, stacking 
sequence), microscale parameters (fiber, matrix, interface and porosities) and surrounding conditions have been discussed. The main features for damping root are summarized in Table 1.

\section{$4 \quad$ Limitations of existing PFC damping studies}

(1) Porosity - The influence of porosity level has been recently investigated for PFCs made of non-woven fabrics and thermoplastic polymer [110]. However, results remain poor in literature in particular for short fibre composites as well as woven fabric based composites. Additional research on this topic regarding different type of PFCs with different matrices (thermoset or thermoplastic) is necessary since not enough conclusion has been reached at this time. In addition to the porosity level, the influence of the size and distribution of porosities should be investigated.

(2) Environmental conditions - The effect of hygrothermal coupling on the damping using different types of PFCs needs more research. At present time, the influence of environmental conditions is generally investigated using DMA tests, involving moisture content variation when sweeping temperature. The use of vibration tests is also recommended in the future to obtain direct measurements in a mid-frequency range.

(3) Characterization at the microscale and multi-scale approach - For the characterization of damping, a large number of reports focus on macro- and meso- scales, while studies on microscale are currently rarely seen. However, this is required to map the damping in the different constituents: plant fiber wall, surrounding matrix and its interface, to better understand the influence of microscale parameters on the damping at 
the macroscale. A particular attention has to be paid on the time scales related to each dissipation phenomena occurring at the various space scale.

(4) Wideband frequency and experimental technique effects - Evolution with frequency - Most of the results obtained for non-woven composites as well as non-crimp and woven composites show that the loss factor varies slightly with the frequency $[43,110]$. Based on these results, it is however sometimes difficult to derive a trend. The combination of data collected using different experimental techniques on a same PFCs is suggested to observe the trend of the loss factor over a wide range of frequencies.

Comparison of experimental techniques - The comparison of different test methods for specific PFCs under the same conditions to know their influential would also constitute valuable analysis for future research since many other influential parameters vary from one study to another.

Use of additional techniques - In parallel to the classical DMA and vibration techniques, other methods such as ultrasonic testing, nano-indentation, and scanning micro-deformation microscopy have been investigated for the damping characterization of polymer [118]. These techniques could also be used for PFCs. Although they are also limited by frequency and temperature, they can complement the limitations of other experiments in multi-scale [70,89]. Wave number-based approaches can be an optional method to deal with high frequency range issues.

(5) Fiber length and microstructure - Even if the influence of fiber length on the damping properties has been already investigated for short-fiber composites, a more in- 
depth study is necessary to better comprehend the influence of fiber length, fiber ends and discontinuities on the damping behavior, in particular in non-crimp fabric composites. For such composites, the influence of fiber type and fiber microstructural features should also be studied.

(6) Stress level effect - Since most of the PFCs exhibit a nonlinear static behavior as a function of the stress level, it would be also interesting to verify the linearity of the damping behavior as a function of the stress level.

(7) Other factors - Composite materials face fatigue issues during long-term service. Some effects of fatigue on damping performance are already reported. The loss factor is shown to decrease substantially in the first cycles, then it slightly decreases, then it stabilizes before the final failure [129]. This deserves to be explained since one may expect an increase of the damping capacity with the damage creation and propagation.

The effect of various coupling conditions such as fatigue, moisture, temperature, etc. on the damping properties of PFCs should be studied in the future.

Besides, different parameter configurations during the composite manufacturing process also have an impact on the damping performance. A study finds that higher pressures appear to reduce the damping ratio due to alterations in the fiber-matrix bond [46]. The influence of parameters in the manufacturing process can be considered in the future. 


\section{Conclusions}

This article critically reviews many factors that affect the damping properties of PFCs in mesoscale parameters, microscale parameters, surrounding conditions, etc. based on recent research reports. Literature shows that PFCs have values of loss factor comprised between $0.7 \%$ and $14 \%$, while values are comprised between $0.24 \%$ and $2.5 \%$ for SFCs. Therefore, the damping capacity of PFCs is generally much higher than SFCs. The damping range is also more widespread. This is linked to the wide variety of fibers and their hierarchical organization and complex composition. The literature review points out also sometimes contradictory results. This is attributed to the wide variety of plant fiber composites studied, involving various types of plant fibers organized in different reinforcement architectures embedded in a very broad set of polymer matrices. This variety prevents sometimes from reaching a consensus and establishing generic conclusion. The review also shows some gaps in knowledge to bridge in the future.

The main conclusions are the following:

(a) The damping characteristics of PFCs are unique because of their microstructural and morphological properties, linked to their polymeric nature, moisture sensitivity, complex interface, finite length when compared to SFCs. Quantitative analysis of the influence of microstructure on damping performance is rarely seen, although there have been many studies on static mechanical properties. 
(b) The diameter-length ratio of plant fiber has a significant effect on the damping of PFCs and different reinforcement types have different trends. The outer layer in the stacking sequence has a considerable effect on damping.

(c) Interface properties between fibers and matrices have a significant effect on damping performance with sometimes contradictory interpretations. Additional studies and knowledge are necessary to shield light of this complex issue.

(d) The special damping mechanisms for plant fiber composites is mainly due to intracell and inter-cell wall friction, intra-yarn, and inter-yarn friction, and fiber/matrix sliding. The effect of treatments on composite damping is caused by the change of interfacial properties between fiber and matrix.

(e) Plant fiber composites are more sensitive to moisture content than synthetic fiber composites because of the mismatch of the moisture expansion coefficients between the matrix and the fiber, which would induce a modification of the interfacial properties.

(f) Future work can expand on these issues regarding the effect on damping properties such as comparison of multiscale experimental method, different reinforcement type, surrounding conditions, parameters in the manufacturing process, etc.

\section{Declaration of competing interest}

The authors declare that they have no known competing financial interests or personal relationships that could have appeared to influence the work reported in this 
paper.

\section{Acknowledgements}

The authors express their gratitude for the funding received from the Bio Based Industries Joint Undertaking under the European Union's Horizon 2020 research and innovation program under grant agreement No. 744349-SSUCHY project and the funding received from the Region Bourgogne-Franche-Comté under grant agreement No. 2016Y06124-D-BCOMP project. Financial support from the EUR EIPHI Graduate school (contract "ANR-17-EURE-0002") is also gratefully acknowledged. 


\section{References}

[1] Chung DDL. Structural composite materials tailored for damping. J. Alloys Compd., vol. 355, 2003, p. 216-23. doi:10.1016/S0925-8388(03)00233-0.

[2] Buravalla VR, Remillat C, Rongong JA, Tomlinson GR. Advances in damping materials and technology. Smart Mater Bull 2001;2001:10-3. doi:10.1016/S1471-3918(01)80184-2.

[3] Väisänen T, Das O, Tomppo L. A review on new bio-based constituents for natural fiber-polymer composites. J Clean Prod 2017;149:582-96. doi:10.1016/j.jclepro.2017.02.132.

[4] Le Duigou A, Bourmaud A, Davies P, Baley C. Long term immersion in natural seawater of Flax/PLA biocomposite. Ocean Eng 2014;90:140-8. doi:10.1016/j.oceaneng.2014.07.021.

[5] Zhang MQ, Rong MZ, Lu X. Fully biodegradable natural fiber composites from renewable resources: All-plant fiber composites. Compos Sci Technol 2005;65:2514-25. doi:10.1016/j.compscitech.2005.06.018.

[6] Zeng X, Rose JG, Rice JS. Stiffness and Damping Ratio of Rubber-Modified Asphalt Mixes: Potential Vibration Attenuation for High-Speed Railway Trackbeds. J Vib Control 2001;7:527-38. doi:10.1177/107754630100700403.

[7] Butaud P, Foltête E, Structures MO-C, 2016 undefined. Sandwich structures with tunable damping properties: On the use of shape memory polymer as viscoelastic core. Elsevier n.d.

[8] Li Z, Vibration MC-IJ of A and, 2005 undefined. A review on vibration damping in sandwich composite structures. IiavOrg n.d.

[9] Wang B, Yang M. Damping of honeycomb sandwich beams. J Mater Process Technol 2000;105:6772. doi:10.1016/S0924-0136(00)00564-1.

[10] Araújo AL, Martins P, Mota Soares CM, Mota Soares CA, Herskovits J. Damping optimization of viscoelastic laminated sandwich composite structures. Struct Multidiscip Optim 2009;39:569-79. doi:10.1007/s00158-009-0390-4.

[11] Mallick P. Fiber-reinforced composites: materials, manufacturing, and design. Third Edit. Boca Raton: CRC Press; 2007. doi:10.1201/9781420005981.

[12] Chandra R, Singh SP, Gupta K. Damping studies in fiber-reinforced composites - a review. Compos Struct 1999;46:41-51. doi:10.1016/S0263-8223(99)00041-0.

[13] Safri SNA, Sultan MTH, Jawaid M, Jayakrishna K. Impact behaviour of hybrid composites for structural applications: A review. Compos Part B Eng 2018;133:112-21. doi:10.1016/j.compositesb.2017.09.008.

[14] Hine PJ, Gusev AA. Validating a micromechanical modelling scheme for predicting the five independent viscoelastic constants of unidirectional carbon fibre composites. Int $J$ Eng Sci 2019;144:103133. doi:10.1016/J.IJENGSCI.2019.103133.

[15] Grunenfelder LK, Dills A, Centea T, Nutt S. Effect of prepreg format on defect control in out-ofautoclave processing. Compos Part A Appl Sci Manuf 2017;93:88-99. doi:10.1016/j.compositesa.2016.10.027.

[16] Liu J, Zhu W, Yu Z, Wei X. Dynamic shear-lag model for understanding the role of matrix in energy dissipation in fiber-reinforced composites. Acta Biomater 2018;74:270-9. doi:10.1016/j.actbio.2018.04.031.

[17] Nguyen XT, Hou S, Liu T, Han X. A potential natural energy absorption material - Coconut mesocarp: Part A: Experimental investigations on mechanical properties. Int J Mech Sci 2016;115-116:564-73. doi:10.1016/j.ijmecsci.2016.07.017.

[18] Joshi S V., Drzal LT, Mohanty AK, Arora S. Are natural fiber composites environmentally superior to glass fiber reinforced composites? Compos Part A Appl Sci Manuf 2004;35:371-6. doi:10.1016/j.compositesa.2003.09.016.

[19] Hardiman M, Vaughan TJ, McCarthy CT. A review of key developments and pertinent issues in nanoindentation testing of fibre reinforced plastic microstructures. Compos Struct 2017;180:782-98. doi:10.1016/j.compstruct.2017.08.004.

[20] Yan L, Chouw N, Jayaraman K. Flax fibre and its composites - A review. Compos Part B Eng 2014;56:296-317. doi:10.1016/j.compositesb.2013.08.014.

[21] Thiruchitrambalam M, Alavudeen A, Venkateshwaran N. Review on kenaf fiber composites. Rev Adv Mater Sci 2012;32:106-12.

[22] Shah DU. Natural fibre composites: Comprehensive Ashby-type materials selection charts. Mater Des 2014;62:21-31. doi:10.1016/j.matdes.2014.05.002.

[23] Ramesh M. Flax (Linum usitatissimum L.) fibre reinforced polymer composite materials: A review 
on preparation, properties and prospects. Prog Mater Sci 2019;102:109-66. doi:10.1016/j.pmatsci.2018.12.004.

[24] Yahaya R, Sapuan S, Jawaid M, Leman Z, Zainudin E. Mechanical performance of woven kenafKevlar hybrid composites. J Reinf Plast Compos 2014;33:2242-54. doi:10.1177/0731684414559864.

[25] Khalfallah M, Abbès B, Abbès F, Guo YQ, Marcel V, Duval A, et al. Innovative flax tapes reinforced Acrodur biocomposites: A new alternative for automotive applications. Mater Des 2014;64. doi:10.1016/j.matdes.2014.07.029.

[26] Hagnell MK, Åkermo M. The economic and mechanical potential of closed loop material usage and recycling of fibre-reinforced composite materials. J Clean Prod 2019;223:957-68. doi:10.1016/J.JCLEPRO.2019.03.156.

[27] Duc F, Bourban PE, Plummer CJGG, Månson JAEE. Damping of thermoset and thermoplastic flax fibre composites. Compos Part A Appl Sci Manuf 2014;64:115-23. doi:10.1016/j.compositesa.2014.04.016.

[28] Margem FM, Monteiro SN, Neto JB, Rodriguez RJS, Soares. BG. The dynamic-Mechanical behavior of epoxy matrix composites reinforced with ramie fibers. 65th ABM Int Congr 18th IFHTSE Congr 1st TMS/ABM Int Mater Congr 2010 2010;6:5003-11. doi:10.1590/s1517-70762010000200012.

[29] Yang Z, Peng H, Wang W, Liu T, M. Jawaid, H.P.S. Abdul Khalil b, Azman Hassan a, Rudi Dungani c AH c, Yang Z, et al. Crystallization behavior of poly( $\varepsilon$-caprolactone)/layered double hydroxide nanocomposites. J Appl Polym Sci 2010;116:2658-67. doi:10.1002/app.

[30] Jawaid M, Abdul Khalil HPS, Hassan A, Dungani R, Hadiyane A. Effect of jute fibre loading on tensile and dynamic mechanical properties of oil palm epoxy composites. Compos Part B Eng 2013;45:619-24. doi:10.1016/j.compositesb.2012.04.068.

[31] Towo AN, Ansell MP. Fatigue evaluation and dynamic mechanical thermal analysis of sisal fibrethermosetting resin composites. Compos Sci Technol 2008;68:925-32. doi:10.1016/j.compscitech.2007.08.022.

[32] Saha AK, Das S, Bhatta D, Mitra BC. Study of Jute Fiber Reinforced Polyester Composites by Dynamic Mechanical Analysis. J Appl Polym Sci 1999;71:1505-13. doi:10.1002/(SICI)10974628(19990228)71:9<1505::AID-APP15>3.0.CO;2-1.

[33] Mylsamy K, Rajendran I. The mechanical properties, deformation and thermomechanical properties of alkali treated and untreated Agave continuous fibre reinforced epoxy composites. Mater Des 2011;32:3076-84. doi:10.1016/j.matdes.2010.12.051.

[34] Suresh Kumar SM, Duraibabu D, Subramanian K. Studies on mechanical, thermal and dynamic mechanical properties of untreated (raw) and treated coconut sheath fiber reinforced epoxy composites. Mater Des 2014;59:63-9. doi:10.1016/j.matdes.2014.02.013.

[35] Sreenivasan VS, Rajini N, Alavudeen A, Arumugaprabu V. Dynamic mechanical and thermogravimetric analysis of Sansevieria cylindrica/polyester composite: Effect of fiber length, fiber loading and chemical treatment. Compos Part B Eng 2015;69:76-86. doi:10.1016/j.compositesb.2014.09.025.

[36] Ray D, Sarkar BK, Das S, Rana AK. Dynamic mechanical and thermal analysis of vinylester-resinmatrix composites reinforced with untreated and alkali-treated jute fibres. Compos Sci Technol 2002;62:911-7. doi:10.1016/S0266-3538(02)00005-2.

[37] Pothan LA, Oommen Z, Thomas S. Dynamic mechanical analysis of banana fiber reinforced polyester composites. Compos Sci Technol 2003;63:283-93. doi:10.1016/S0266-3538(02)00254-3.

[38] Daoud H, El Mahi A, Rebière JL, Taktak M, Haddar M. Characterization of the vibrational behaviour of flax fibre reinforced composites with an interleaved natural viscoelastic layer. Appl Acoust 2017;128:23-31. doi:10.1016/j.apacoust.2016.12.005.

[39] Shinoj S, Visvanathan R, Panigrahi S, Varadharaju N. Dynamic mechanical properties of oil palm fibre (OPF)-linear low density polyethylene (LLDPE) biocomposites and study of fibre-matrix interactions. Biosyst Eng 2011;109:99-107. doi:10.1016/j.biosystemseng.2011.02.006.

[40] Karaduman Y, Sayeed MMA, Onal L, Rawal A. Viscoelastic properties of surface modified jute fiber/polypropylene nonwoven composites. Compos Part B Eng 2014;67:111-8. doi:10.1016/j.compositesb.2014.06.019.

[41] Mohanty S, Verma SK, Nayak SK. Dynamic mechanical and thermal properties of MAPE treated jute/HDPE composites. Compos Sci Technol 2006;66:538-47. doi:10.1016/j.compscitech.2005.06.014.

[42] Etaati A, Mehdizadeh SA, Wang H, Pather S. Vibration damping characteristics of short hemp fibre thermoplastic composites. J Reinf Plast Compos 2014;33:330-41. doi:10.1177/0731684413512228.

[43] Amenini F, Brocail J, Chauvin M, Thuillier S. Dynamical properties of flax fibre reinforced PA11 over a large frequency range. Compos Sci Technol 2019;171:234-43. doi:10.1016/j.compscitech.2018.12.026.

[44] Mahmoudi S, Kervoelen A, Robin G, Duigou L, Daya EM, Cadou JM. Experimental and numerical 
investigation of the damping of flax-epoxy composite plates. Compos Struct 2019;208:426-33. doi:10.1016/j.compstruct.2018.10.030.

[45] Li Y, Cai S, Huang X. Multi-scaled enhancement of damping property for carbon fiber reinforced composites. Compos Sci Technol 2017;143:89-97. doi:10.1016/j.compscitech.2017.03.008.

[46] Ashworth S, Rongong J, Wilson P, Meredith J. Mechanical and damping properties of resin transfer moulded jute-carbon hybrid composites. Compos Part B Eng 2016;105:60-6. doi:10.1016/j.compositesb.2016.08.019.

[47] Cihan M, Sobey AJ, Blake JIR. Mechanical and dynamic performance of woven flax/E-glass hybrid composites. Compos Sci Technol 2019;172:36-42. doi:10.1016/j.compscitech.2018.12.030.

[48] Zhang J, Khatibi AA, Castanet E, Baum T, Komeily-Nia Z, Vroman P, et al. Effect of natural fibre reinforcement on the sound and vibration damping properties of bio-composites compression moulded by nonwoven mats. Compos Commun 2019;13:12-7. doi:10.1016/j.coco.2019.02.002.

[49] Essabir H, Elkhaoulani A, Benmoussa K, Bouhfid R, Arrakhiz FZ, Qaiss A. Dynamic mechanical thermal behavior analysis of doum fibers reinforced polypropylene composites. Mater Des 2013;51:780-8. doi:10.1016/j.matdes.2013.04.092.

[50] El-Hafidi A, Gning PB, Piezel B, Belaïd M, Fontaine S. Determination of dynamic properties of flax fibres reinforced laminate using vibration measurements. Polym Test 2017;57:219-25. doi:10.1016/j.polymertesting.2016.11.035.

[51] Brodt M, Lakes RS. Composite Materials Which Exhibit High Stiffness and High Viscoelastic Damping. J Compos Mater 1995;29:1823-33. doi:10.1177/002199839502901402.

[52] Lakes R, Lakes R. Viscoelastic materials 2009.

[53] Lakes RS. High damping composite materials: Effect of structural hierarchy. J Compos Mater 2002;36:287-97. doi:10.1177/0021998302036003538.

[54] Ashby MF. Materials selection in mechanical design. FAE RIVISTE-FRANCO ANGELI EDITORE RIVISTE; 1994.

[55] Adams V, Askenazi A. Building Better Products with Finite Element Analysis. Santa Fe: Onword Press; 1999.

[56] Ashby MF. Materials selection in mechanical design. Butterworth-Heinemann; 2010.

[57] Liang Z, Pan P, Zhu B, Dong T, Inoue Y. Mechanical and thermal properties of poly(butylene succinate)/plant fiber biodegradable composite. J Appl Polym Sci 2010;115:3559-67. doi:10.1002/app.29848.

[58] Le Guen MJ, Newman RH, Fernyhough A, Emms GW, Staiger MP. The damping-modulus relationship in flax-carbon fibre hybrid composites. Compos Part B Eng 2016;89:27-33. doi:10.1016/j.compositesb.2015.10.046.

[59] Assarar M, Zouari W, Sabhi H, Ayad R, Berthelot JM. Evaluation of the damping of hybrid carbonflax reinforced composites. Compos Struct 2015;132:148-54. doi:10.1016/j.compstruct.2015.05.016.

[60] Rueppel M, Rion J, Dransfeld C, Fischer C, Masania K. Damping of carbon fibre and flax fibre angleply composite laminates. Compos Sci Technol 2017;146:1-9. doi:10.1016/j.compscitech.2017.04.011.

[61] Madera-Santana TJ, Misra M, Drzal LT, Robledo D, Freile-Pelegrin Y. Preparation and characterization of biodegradable agar/poly(butylene adipateco-terephatalate) composites. Polym Eng Sci 2009;49:1117-26. doi:10.1002/pen.21389.

[62] Mazuki AAM, Akil HM, Safiee S, Ishak ZAM, Bakar AA. Degradation of dynamic mechanical properties of pultruded kenaf fiber reinforced composites after immersion in various solutions. Compos Part B Eng 2011;42:71-6. doi:10.1016/j.compositesb.2010.08.004.

[63] Lakes R. Viscoelastic solids. CRC Press; 1998.

[64] Gibson RF. Damping characteristics of composite materials and structures. J Mater Eng Perform 1992;1:11-20. doi:10.1007/BF02650027.

[65] Chandra R, Singh S, structures KG-C, 1999 undefined. Damping studies in fiber-reinforced composites-a review. Elsevier n.d.

[66] Gibson R, Hwang S, SAMPE HK-P of 36th I, 1991 U. Micromechanical modeling of damping in composites including interphase effects. 36th Int. Soc. Adv. Mater. Process Eng., 1991.

[67] Nelson DJ, Hancock JW. Interfacial slip and damping in fibre reinforced composites. J Mater Sci 1978;13:2429-40. doi:10.1007/BF00808058.

[68] Duc F, Bourban PE, Månson JAE. The role of twist and crimp on the vibration behaviour of flax fibre composites. Compos Sci Technol 2014;102:94-9. doi:10.1016/j.compscitech.2014.07.004.

[69] Menrad K. Dynamic Mechanical Analysis: A Practical Introduction 2008.

[70] Butaud P, Placet V, Klesa J, Ouisse M, Foltête E, Gabrion X. Investigations on the frequency and temperature effects on mechanical properties of a shape memory polymer (Veriflex). Mech Mater 2015;87:50-60. doi:10.1016/j.mechmat.2015.04.002. 
[71] Martínez-Hernández AL, Velasco-Santos C, de-Icaza M, Castaño VM. Dynamical-mechanical and thermal analysis of polymeric composites reinforced with keratin biofibers from chicken feathers. Compos Part B Eng 2007;38:405-10. doi:10.1016/j.compositesb.2006.06.013.

[72] Singh SP, Smith JF, Singh RP. Characterization of the damping behavior of a nanoindentation instrument for carrying out dynamic experiments. Exp Mech 2008;48:571-83. doi:10.1007/s11340-0079117-x.

[73] Kuzak SG, Shanmugam A. Dynamic mechanical analysis of fiber-reinforced phenolics. J Appl Polym Sci 1999;73:649-58. doi:10.1002/(SICI)1097-4628(19990801)73:5<649::AID-APP5>3.0.CO;2-B.

[74] Placet V, Foltête E. Is dynamic mechanical analysis (DMA) a non-resonance technique? EPJ Web Conf 2010;6:41004. doi:10.1051/epjconf/20100641004.

[75] Bhudolia SK, Perrotey P, Joshi SC. Enhanced vibration damping and dynamic mechanical characteristics of composites with novel pseudo-thermoset matrix system. Compos Struct 2017;179:50213. doi:10.1016/j.compstruct.2017.07.093.

[76] Wielage B, Lampke T, Utschick H, Soergel F. Processing of natural-fibre reinforced polymers and the resulting dynamic-mechanical properties. J Mater Process Technol 2003;139:140-6. doi:10.1016/S09240136(03)00195-X.

[77] Theotokoglou EE, Giannopoulos I, Sideridis E. Analytical, experimental and numerical approach of storage and loss moduli of fibre reinforced epoxy composites. ICCM Int Conf Compos Mater 2015;2015July:19-24.

[78] Gibson RF. Modal vibration response measurements for characterization of composite materials and structures. Compos Sci Technol 2000;60:2769-80. doi:10.1016/S0266-3538(00)00092-0.

[79] Mishra I, Shishir \&, Sahu K. An experimental approach to free vibration response of woven fiber composite plates under free-free boundary condition. 2012.

[80] Ouisse M, Renault D, Butaud P, Sadoulet E, Sadoulet-Reboul E. Damping control for improvement of acoustic black hole effect. J Sound Vib 2019:63-72. doi:10.1016/j.jsv.2019.04.029i.

[81] Matter M, Gmür T, Cugnoni J, Schorderet A. Numerical-experimental identification of the elastic and damping properties in composite plates. Compos Struct 2009;90:180-7. doi:10.1016/j.compstruct.2009.03.001.

[82] Alexander J, Augustine BSM, Prudhuvi S, Paudel A. Hygrothermal effect on natural frequency and damping characteristics of basalt/epoxy composites. Mater Today Proc 2016;3:1666-71. doi:10.1016/j.matpr.2016.04.057.

[83] López-Aenlle M, Noriega A, Pelayo F. Mechanical characterization of polyvinil butyral from static and modal tests on laminated glass beams. Compos Part B Eng 2019;169:9-18. doi:10.1016/j.compositesb.2019.03.077.

[84] Rao MD, Echempati R, Nadella S. Dynamic analysis and damping of composite structures embedded with viscoelastic layers. Compos Part B Eng 1997;28:547-54. doi:10.1016/S1359-8368(96)00073-X.

[85] ASTM E756 - 05(2017) Standard Test Method for Measuring Vibration-Damping Properties of Materials n.d. doi:10.1520/E0756-05R17.

[86] Oberst H, Frankenfeld K. Über die Dämpfung der Biegeschwingungen dünner Bleche durch fest haftende Beläge. Acta Acust United with Acust 1952;2:181-94.

[87] Koruk H, Sanliturk KY. Identification and removal of adverse effects of non-contact electromagnetic excitation in Oberst Beam Test Method. Mech Syst Signal Process 2012;30:274-95. doi:10.1016/j.ymssp.2012.02.003.

[88] Viala R, Placet V, Cogan S. Identification of the anisotropic elastic and damping properties of complex shape composite parts using an inverse method based on finite element model updating and 3D velocity fields measurements (FEMU-3DVF): Application to bio-based composite violin sou. Compos Part A Appl Sci Manuf 2018;106:91-103. doi:10.1016/j.compositesa.2017.12.018.

[89] Butaud P, Ouisse M, Placet V, Renaud F, Travaillot T, Maynadier A, et al. Identification of the viscoelastic properties of the tBA/PEGDMA polymer from multi-loading modes conducted over a wide frequency-temperature scale range. Polym Test 2018;69:250-8. doi:10.1016/j.polymertesting.2018.05.030. [90] Ege K, Boutillon X, David B. High-resolution modal analysis. J Sound Vib 2009;325:852-69. doi:10.1016/j.jsv.2009.04.019.

[91] Marchetti F, Ege K, Leclère Q, Roozen NB. On the structural dynamics of laminated composite plates and sandwich structures; a new perspective on damping identification. J Sound Vib 2020;474:115256. doi:10.1016/j.jsv.2020.115256.

[92] Duval A, Marcel V, Dejaeger L, Lhuillier F, Khalfallah M. Vibro-acoustic properties of a very long flax fibers reinforced thermoset "flaxpreg" light sandwich. SAE Tech. Pap., vol. 2015- June, SAE International; 2015. doi:10.4271/2015-01-2345.

[93] Senthil Kumar K, Siva I, Jeyaraj P, Winowlin Jappes JT, Amico SC, Rajini N. Synergy of fiber length 
and content on free vibration and damping behavior of natural fiber reinforced polyester composite beams. Mater Des 2014;56:379-86. doi:10.1016/j.matdes.2013.11.039.

[94] Bledzki AK, Gassan J. Composites reinforced with cellulose based fibres. Prog Polym Sci 1999;24:221-74. doi:10.1016/S0079-6700(98)00018-5.

[95] Subramanian C, Deshpande SB, Senthilvelan S. Effect of reinforced fiber length on the damping performance of thermoplastic composites. Adv Compos Mater 2011;20:319-35. doi:10.1163/092430410X550872.

[96] Harris B, Braddell OG, Almond DP, Lefebvre C, Verbist J. Study of carbon fibre surface treatments by dynamic mechanical analysis. J Mater Sci 1993;28:3353-66. doi:10.1007/BF00354259.

[97] Rezaei F, Yunus R, Ibrahim NA. Effect of fiber length on thermomechanical properties of short carbon fiber reinforced polypropylene composites. Mater Des 30:260-3. doi:10.1016/j.matdes.2008.05.005.

[98] Audibert C, Andreani AS, Lainé É, Grandidier JC. Mechanical characterization and damage mechanism of a new flax-Kevlar hybrid/epoxy composite. Compos Struct 2018;195:126-35. doi:10.1016/j.compstruct.2018.04.061.

[99] Rouf K, Denton NL, French RM. Effect of fabric weaves on the dynamic response of two-dimensional woven fabric composites. J Mater Sci 2017;52:10581-91. doi:10.1007/s10853-017-1183-6.

[100] Alkbir MFM, Sapuan SM, Nuraini AA, Ishak MR. Fibre properties and crashworthiness parameters of natural fibre-reinforced composite structure: A literature review. Compos Struct 2016;148:59-73. doi:10.1016/j.compstruct.2016.01.098.

[101] Rajesh M, Pitchaimani J. Dynamic mechanical analysis and free vibration behavior of intra-ply woven natural fiber hybrid polymer composite. J Reinf Plast Compos 2016;35:228-42. doi:10.1177/0731684415611973.

[102] Duc F, Bourban PE, Månson JAE. Dynamic mechanical properties of epoxy/flax fibre composites. J Reinf Plast Compos 2014;33:1625-33. doi:10.1177/0731684414539779.

[103] Senthilkumar K, Siva I, Sultan MTH, Rajini N, Siengchin S, Jawaid M, et al. Static and dynamic properties of sisal fiber polyester composites - Effect of interlaminar fiber orientation. BioResources 2017;12:7819-33. doi:10.15376/biores.12.4.7819-7833.

[104] Pothan LA, Mai YW, Thomas S, Li RKY. Tensile and Flexural Behavior of Sisal Fabric/Polyester Textile Composites Prepared by Resin Transfer Molding Technique n.d. doi:10.1177/0731684408090342.

[105] Fiore V, Di Bella G, Valenza A. The effect of alkaline treatment on mechanical properties of kenaf fibers and their epoxy composites. Compos Part B Eng 2015;68:14-21. doi:10.1016/j.compositesb.2014.08.025.

[106] Ramraji K, Rajkumar K, Sabarinathan P. Mechanical and free vibration properties of skin and core designed basalt woven intertwined with flax layered polymeric laminates. Proc Inst Mech Eng Part C J Mech Eng Sci 2020:095440622092225. doi:10.1177/0954406220922257.

[107] Rajesh M, Pitchaimani J, Rajini N. Free Vibration Characteristics of Banana/Sisal Natural Fibers Reinforced Hybrid Polymer Composite Beam. Procedia Eng., vol. 144, Elsevier Ltd; 2016, p. 1055-9. doi:10.1016/j.proeng.2016.05.056.

[108] Pan P, Zhu B, Dong T, Serizawa S, Iji M, Inoue Y. Kenaf fiber/poly( $\varepsilon$-caprolactone) biocomposite with enhanced crystallization rate and mechanical properties. J Appl Polym Sci 2008;107:3512-9. doi:10.1002/app.27470.

[109] Hwang SJ, Gibson RF. Contribution of interlaminar stresses to damping in thick laminated composites under uniaxial extension. Compos Struct 1992;20:29-35. doi:10.1016/0263-8223(92)90009-2.

[110] Hadiji H, Assarar M, Zouari W, Pierre F, Behlouli K, Zouari B, et al. Damping analysis of nonwoven natural fibre-reinforced polypropylene composites used in automotive interior parts. Polym Test 2020;89:106692. doi:10.1016/j.polymertesting.2020.106692.

[111] Bourmaud A, Morvan C, Bouali A, Placet V, Perré P, Baley C. Relationships between microfibrillar angle, mechanical properties and biochemical composition of flax fibers. Ind Crops Prod 2013;44:343-51. doi:10.1016/j.indcrop.2012.11.031.

[112] Ismail AS, Jawaid M, Naveen J. Void content, tensile, vibration and acoustic properties of kenaf/bamboo fiber reinforced epoxy hybrid composites. Materials (Basel) 2019;12. doi:10.3390/ma12132094.

[113] Chandradass J, Kumar M, Letters RV-M, 2007 undefined. Effect of nanoclay addition on vibration properties of glass fibre reinforced vinyl ester composites. Elsevier n.d.

[114] Kumar K, Siva I, Rajini N, Jappes J, Design SA-M\&, 2016 undefined. Layering pattern effects on vibrational behavior of coconut sheath/banana fiber hybrid composites. Elsevier n.d.

[115] Sathishkumar TP, Naveen J, Satheeshkumar S. Hybrid fiber reinforced polymer composites-a review n.d. doi:10.1177/0731684413516393. 
[116] le Duigou A, Merotte J, Bourmaud A, Davies P, Belhouli K, Baley C. Hygroscopic expansion: A key point to describe natural fibre/polymer matrix interface bond strength. Compos Sci Technol 2017;151:228-33. doi:10.1016/j.compscitech.2017.08.028.

[117] Bourmaud A, Gibaud M, Baley C. Impact of the seeding rate on flax stem stability and the mechanical properties of elementary fibres. Ind Crops Prod 2016;80. doi:10.1016/j.indcrop.2015.10.053.

[118] Baley C, Gomina M, Breard J, Bourmaud A, Davies P. Industrial Crops \& Products Variability of mechanical properties of flax fibres for composite reinforcement . A review. Ind Crop Prod 2019:111984. doi:10.1016/j.indcrop.2019.111984.

[119] Li Y, Yi X, Yu T, Xian G. An overview of structural-functional-integrated composites based on the hierarchical microstructures of plant fibers. Adv Compos Hybrid Mater 2018;1:231-46. doi:10.1007/s42114-017-0020-3.

[120] Hosseinaei O, Wang S, Rials TG, Xing C, Zhang Y. Effects of decreasing carbohydrate content on properties of wood strands. Cellulose 2011;18:841-50. doi:10.1007/s10570-011-9519-X.

[121] Goubet F, Jackson P, Deery MJ, Dupree P. Polysaccharide analysis using carbohydrate gel electrophoresis. A method to study plant cell wall polysaccharides and polysaccharide hydrolases. Anal Biochem 2002;300:53-68. doi:10.1006/abio.2001.5444.

[122] Keryvin V, Lan M, Bourmaud A, Parenteau T, Charleux L, Baley C. Analysis of flax fibres viscoelastic behaviour at micro and nano scales. Compos Part A Appl Sci Manuf 2015;68:219-25. doi:10.1016/j.compositesa.2014.10.006.

[123] Cisse O, Placet V, Guicheret-Retel V, Trivaudey F, Boubakar ML. Creep behaviour of single hemp fibres. Part I: viscoelastic properties and their scattering under constant climate. J Mater Sci 2015;50:1996-2006. doi:10.1007/s10853-014-8767-1.

[124] Van Hazendonk JM, Reinerik EJM, De Waard P, Van Dam JEG. Structural analysis of acetylated hemicellulose polysaccharides from fibre flax (Linum usitatissimum L.). Carbohydr Res 1996;291:141-54. doi:10.1016/S0008-6215(96)00160-7.

[125] Biagiotti J, Puglia D, Kenny JM. A review on natural fibre-based composites - Part I: Structure, processing and properties of vegetable fibres. J Nat Fibers 2004;1:37-68. doi:10.1300/J395v01n02_04.

[126] Bismarck A, Aranberri-Askargorta I, Springer J, Lampke T, Wielage B, Stamboulis A, et al. Surface characterization of flax, hemp and cellulose fibers; Surface properties and the water uptake behavior. Polym Compos 2002;23:872-94. doi:10.1002/pc.10485.

[127] Jeannin T, Berges M, Gabrion X, Léger R, Person V, Corn S, et al. Influence of hydrothermal ageing on the fatigue behaviour of a unidirectional flax-epoxy laminate. Compos Part B Eng 2019;174:107056. doi:10.1016/j.compositesb.2019.107056.

[128] Jeannin T, Gabrion X, Ramasso E, Placet V. About the fatigue endurance of unidirectional flaxepoxy composite laminates. Compos Part B Eng 2019;165:690-701. doi:10.1016/j.compositesb.2019.02.009.

[129] Haggui M, El Mahi A, Jendli Z, Akrout A, Haddar M. Static and fatigue characterization of flax fiber reinforced thermoplastic composites by acoustic emission. Appl Acoust 2019;147:100-10. doi:10.1016/j.apacoust.2018.03.011.

[130] Launay A, Marco Y, Maitournam MH, Raoult I. Modelling the influence of temperature and relative humidity on the time-dependent mechanical behaviour of a short glass fibre reinforced polyamide. Mech Mater 2013;56:1-10. doi:10.1016/j.mechmat.2012.08.008.

[131] Zai BA, Park MK, Choi HS, Mehboob H, Ali R. Effect of moisture absorption on damping and dynamic stiffness of carbon fiber/epoxy composites. J Mech Sci Technol 2009;23:2998-3004. doi:10.1007/s12206-009-0908-0.

[132] Berthelot J-MM, Assarar M, Sefrani Y, Mahi A El. Damping analysis of composite materials and structures. Compos Struct 2008;85:189-204. doi:10.1016/j.compstruct.2007.10.024.

[133] Placet V. Characterization of the thermo-mechanical behaviour of Hemp fibres intended for the manufacturing of high performance composites. Compos Part A Appl Sci Manuf 2009;40:1111-8. doi:10.1016/j.compositesa.2009.04.031.

[134] Bourmaud A, Baley C. Rigidity analysis of polypropylene/vegetal fibre composites after recycling. Polym Degrad Stab 2009;94:297-305. doi:10.1016/j.polymdegradstab.2008.12.010.

[135] Perrier A, Le Bourhis E, Touchard F, Chocinski-Arnault L. Effect of water ageing on nanoindentation response of single hemp yarn/epoxy composites. Compos Part A Appl Sci Manuf 2016;84:216-23. doi:10.1016/j.compositesa.2016.01.022.

[136] Khelfa H, Gargouri M. IDENTIFICATION DES PROPRIÉTÉS D’ÉLASTICITÉ ET D'AMORTISSEMENT D'UNE FIBRE ISOLÉE ANISOTROPE PAR ULTRASONS LASER Ouverture au cas des fibres naturelles JURY. Le Mans, 2015.

[137] Tahan Latibari S, Mehrali M, Mottahedin L, Fereidoon A, Metselaar HSC. Investigation of 
interfacial damping nanotube-based composite. Compos Part B Eng 2013;50:354-61. doi:10.1016/j.compositesb.2013.02.022.

[138] Joseph S, Appukuttan SP, Kenny JM, Puglia D, Thomas S, Joseph K. Dynamic mechanical properties of oil palm microfibril-reinforced natural rubber composites. J Appl Polym Sci 2010;117:1298308. doi:10.1002/app.30960.

[139] J. George S, Bhagawan SS, Thomas S, George J, Bhagawan SS, Thomas S. Thermogravimetric and dynamic mechanical thermal analysis of pineapple fibre reinforced polyethylene composites. $\mathrm{J}$ Therm Anal 1996;47:1121-40. doi:10.1007/BF01979452.

[140] Zhao D, Hamada H, Yang Y. Influence of polyurethane dispersion as surface treatment on mechanical, thermal and dynamic mechanical properties of laminated woven carbon-fiber-reinforced polyamide 6 composites. Compos Part B Eng 2019;160:535-45. doi:10.1016/j.compositesb.2018.12.105.

[141] Fay JJ, Murphy CJ, Thomas DA, Sperling LH. Effect of morphology, crosslink density, and miscibility on interpenetrating polymer network damping effectiveness. Polym Eng Sci 1991;31:1731-41. doi:10.1002/pen.760312407.

[142] Yu T, Ren J, Li S, Yuan H, Li Y. Effect of fiber surface-treatments on the properties of poly(lactic acid)/ramie composites. Compos Part A Appl Sci Manuf 2010;41:499-505. doi:10.1016/j.compositesa.2009.12.006.

[143] Zierdt P, Theumer T, Kulkarni G, Däumlich V, Klehm J, Hirsch U, et al. Sustainable woodplastic composites from bio-based polyamide 11 and chemically modified beech fibers. Sustain Mater Technol 2015;6:6-14. doi:10.1016/j.susmat.2015.10.001.

[144] Gassan J, Bledzki AK. Possibilities for improving the mechanical properties of jute/epoxy composites by alkali treatment of fibres. Compos Sci Technol 1999;59:1303-9. doi:10.1016/S02663538(98)00169-9.

[145] Dayo AQ, Zegaoui A, Nizamani AA, Kiran S, Wang J, Derradji M, et al. The influence of different chemical treatments on the hemp fiber/polybenzoxazine based green composites: Mechanical, thermal and water absorption properties. Mater Chem Phys 2018;217:270-7. doi:10.1016/j.matchemphys.2018.06.040.

[146] Atiqah A, Jawaid M, Sapuan SM, Ishak MR. Dynamic mechanical properties of sugar palm/glass fiber reinforced thermoplastic polyurethane hybrid composites. Polym Compos 2019;40:1329-34. doi:10.1002/pc.24860.

[147] Li X, Tabil LG, Panigrahi S. Chemical treatments of natural fiber for use in natural fiberreinforced composites: A review. J Polym Environ 2007;15:25-33. doi:10.1007/s10924-006-0042-3.

[148] Zhou F, Cheng G, Jiang B. Effect of silane treatment on microstructure of sisal fibers. Appl Surf Sci 2014;292:806-12. doi:10.1016/j.apsusc.2013.12.054.

[149] Zahari WZW, Badri RNRL, Ardyananta H, Kurniawan D, Nor FM. Mechanical Properties and Water Absorption Behavior of Polypropylene / Ijuk Fiber Composite by Using Silane Treatment. Procedia Manuf 2015;2:573-8. doi:10.1016/j.promfg.2015.07.099.

[150] Yadav A, Gupta MK. Development and characterization of jute composites for sustainable product: Effect of chemical treatments and polymer coating. Mater Res Express 2019. doi:10.1088/20531591/ab5bd9.

[151] Tajvidi M, Motie N, Rassam G, Falk RH, Felton C. Mechanical performance of hemp fiber polypropylene composites at different operating temperatures. J Reinf Plast Compos 2010;29:664-74. doi:10.1177/0731684408100266.

[152] Salleh FM, Hassan A, Yahya R, Azzahari AD. Effects of extrusion temperature on the rheological, dynamic mechanical and tensile properties of kenaf fiber/HDPE composites. Compos Part B Eng 2014;58:259-66. doi:10.1016/j.compositesb.2013.10.068.

[153] Sathishkumar G, Sivabalan S, Joseph Irudaya Raja S, Sivaganesan S. Vibration and viscoelastic characteristics of sisal fiber reinforced polyester composite. Int J Mech Prod Eng Res Dev 2018;2018:329_ 38 .

[154] Daoud H, Rebière JL, Makni A, Taktak M, El Mahi A, Haddar M. Numerical and experimental characterization of the dynamic properties of flax fiber reinforced composites. Int J Appl Mech 2016;8. doi:10.1142/S175882511650068X.

[155] Rahman MZ, Jayaraman K, Mace BR. Vibration damping of flax fibre-reinforced polypropylene composites. Fibers Polym 2017;18:2187-95. doi:10.1007/s12221-017-7418-y.

[156] Berthelot JM, Sefrani Y. Damping analysis of unidirectional glass and Kevlar fibre composites. Compos Sci Technol 2004;64:1261-78. doi:10.1016/j.compscitech.2003.10.003.

[157] Gao Y, Li Y, Hong Y, Zhang H, He X. Modeling of the damping properties of unidirectional carbon fibre composites. Polym Polym Compos 2011;19:119-22. doi:10.1177/0967391111019002-311.

[158] Adams R, Compounds MM-J of A and, 2003 undefined. Damping in advanced polymer- 
matrix composites. Elsevier n.d.

[159] dos Santos Silva G, Capela C, Gaspar M. Developing Sustainable Materials for Marine Environments: Algae as Natural Fibers on Polymer Composites, 2020, p. 198-205. doi:10.1007/978-3-03029041-2_25.

[160] Fu W, Chung DDL. Vibration reduction ability of polymers, particularly polymethylmethacrylate and polytetrafluoroethylene. Polym Polym Compos 2001;9:423-6. doi:10.1177/096739110100900607.

[161] Tung C -J, Hsu TJ. Vibration damping with urethane/acrylate simultaneous semi-interpenetrating polymer networks. J Appl Polym Sci 1992;46:1759-73. doi:10.1002/app.1992.070461007.

[162] Treviso A, Van Genechten B, Mundo D, Tournour M. Damping in composite materials: Properties and models. Compos Part B Eng 2015;78:144-52. doi:10.1016/j.compositesb.2015.03.081.

[163] Jonoobi M, Harun J, Mathew AP, Oksman K. Mechanical properties of cellulose nanofiber (CNF) reinforced polylactic acid (PLA) prepared by twin screw extrusion. Compos Sci Technol 2010;70:1742-7. doi:10.1016/j.compscitech.2010.07.005.

[164] Landel R, Nielsen L. Mechanical properties of polymers and composites. Vol. 21974.

[165] Essabir H, Achaby MEI, Hilali EM, Bouhfid R, Qaiss AEi. Morphological, Structural, Thermal and Tensile Properties of High Density Polyethylene Composites Reinforced with Treated Argan Nut Shell Particles. J Bionic Eng 2015;12:129-41. doi:10.1016/S1672-6529(14)60107-4.

[166] Geethamma V, Kalaprasad G, ... GG-CPA, 2005 undefined. Dynamic mechanical behavior of short coir fiber reinforced natural rubber composites. Elsevier n.d.

[167] Datta C, Basu D, Banerjee A. Mechanical and dynamic mechanical properties of jute fibersnovolac-epoxy composite laminates. J Appl Polym Sci 2002;85:2800-7. doi:10.1002/app.10819.

[168] Wingard CD, Beatty CL. Crosslinking of an epoxy with a mixed amine as a function of stoichiometry. II. Final properties via dynamic mechanical spectroscopy. J Appl Polym Sci 1990;41:2539_54. doi:10.1002/app.1990.070411101.

[169] Otaigbe JU. Dynamic mechanical response of a thermoplastic sheet molding compound-glass fiber composite. Polym Eng Sci 1991;31:104-9. doi:10.1002/pen.760310208.

[170] Kishi H, Kuwata M, Matsuda S, Asami T, Murakami A. Damping properties of thermoplasticelastomer interleaved carbon fiber-reinforced epoxy composites. Compos Sci Technol 2004;64:2517-23. doi:10.1016/j.compscitech.2004.05.006.

[171] Merotte J, Le Duigou A, Bourmaud A, Behlouli K, Baley C. Mechanical and acoustic behaviour of porosity controlled randomly dispersed flax/PP biocomposite. Polym Test 2016;51:174-80. doi:10.1016/j.polymertesting.2016.03.002.

[172] Zoghaib L, Mattei P-O. Damping analysis of a free aluminum plate. J Vib Control 2015;21:208398. doi:10.1177/1077546313507098.

[173] Cheour K, Assarar M, Scida D, Ayad R, Gong X-LL. Effect of water ageing on the mechanical and damping properties of flax-fibre reinforced composite materials. Compos Struct 2016;152:259-66. doi:10.1016/j.compstruct.2016.05.045.

[174] Ben Ameur M, El Mahi A, Rebiere JL, Abdennadher M, Haddar M. Damping analysis of unidirectional carbon/flax fiber hybrid composites. Int J Appl Mech 2018;10. doi:10.1142/S1758825118500503.

[175] Zhang PQ, Ruan JH, Li WZ. Influence of some factors on the damping property of fiberreinforced epoxy composites at low temperature. Cryogenics (Guildf) 2001;41:245-51. doi:10.1016/S0011-2275(01)00076-5.

[176] Péron M, Célino A, Castro M, Jacquemin F, Duigou A Le. Study of hygroscopic stresses in asymmetric biocomposite laminates. Compos Sci Technol 2019;169:7-15. doi:10.1016/j.compscitech.2018.10.027.

[177] Senthilrajan S, Venkateshwaran N. Ageing and Its Influence on Vibration Characteristics of Jute/Polyester Composites. J Polym Environ 2019;27:2144-55. doi:10.1007/s10924-019-01493-0.

[178] Rong MZ, Zhang MQ, Liu Y, Yang GC, Zeng HM. The effect of fiber treatment on the mechanical properties of unidirectional sisal-reinforced epoxy composites. Compos Sci Technol 2001;61:1437-47. doi:10.1016/S0266-3538(01)00046-X.

[179] Lu MM, Van Vuure AW. Improving moisture durability of flax fibre composites by using nondry fibres. Compos Part A Appl Sci Manuf 2019;123:301-9. doi:10.1016/j.compositesa.2019.05.029.

[180] Saxena M, Pappu A, Haque R, Sharma A. Sisal Fiber Based Polymer Composites and Their Applications. Cellul. Fibers Bio- Nano-Polymer Compos., Springer Berlin Heidelberg; 2011, p. 589-659. doi:10.1007/978-3-642-17370-7_22.

[181] Machado JS, Santos S, Pinho FFSS, Luís F, Alves A, Simões R, et al. Impact of high moisture conditions on the serviceability performance of wood plastic composite decks. Mater Des 2016;103:122- 
31. doi:10.1016/j.matdes.2016.04.030.

[182] Bal S, Mahesh D, Sen TK, Ray BC. Effect of Changing Environments on Microstructure of HDPE Polymer. J Miner Mater Charact Eng 2007;06:1-16. doi:10.4236/jmmce.2007.61001.

[183] Cheng Q, Muszynski L, Shaler S, Wang J. Microstructural changes in wood plastic composites due to wetting and re-drying evaluated by X-ray microtomography. J Nondestruct Eval 2010;29:207-13. doi:10.1007/s10921-010-0078-0.

[184] Gerald Arul Selvan M, Athijayamani A. Mechanical properties of fragrant screwpine fiber reinforced unsaturated polyester composite: Effect of fiber length, fiber treatment and water absorption. Fibers Polym 2016;17:104-16. doi:10.1007/s12221-016-5593-X.

[185] Hamid M, Ghani MA, Products SA-IC and, 2012 undefined. Effect of antioxidants and fire retardants as mineral fillers on the physical and mechanical properties of high loading hybrid biocomposites reinforced with rice husks. Elsevier n.d.

[186] Bogren KM, Gamstedt EK, Neagu RC, AÅkerholm M, LindstroÖm M. Dynamic-Mechanical Properties of Wood-Fiber Reinforced Polylactide: Experimental Characterization and Micromechanical Modeling. J Thermoplast Compos Mater 2006;19:613-37. doi:10.1177/0892705706067480.

[187] Gu H. Dynamic mechanical analysis of the seawater treated glass/polyester composites. Mater Des 2009;30:2774-7. doi:10.1016/j.matdes.2008.09.029.

[188] Berges M, Léger R, Placet V, Person V, Corn S, Gabrion X, et al. Influence of moisture uptake on the static, cyclic and dynamic behaviour of unidirectional flax fibre-reinforced epoxy laminates. Compos Part A Appl Sci Manuf 2016;88:165-77. doi:10.1016/j.compositesa.2016.05.029.

[189] Fraga AN, Alvarez VA, Vázquez A, De La Osa O. Relationship between dynamic mechanical properties and water absorption of unsaturated polyester and vinyl ester glass fiber composites. J Compos Mater 2003;37:1553-74. doi:10.1177/0021998303029421.

[190] Almgren KM, Åkerholm M, Gamstedt EK, Salmen L, Lindström M. Effects of Moisture on Dynamic Mechanical Properties of Wood Fiber Composites Studied by Dynamic FT-IR Spectroscopy. J Reinf Plast Compos 2008;27:1709-21. doi:10.1177/0731684407084663.

[191] Ghasemzadeh S, Haddadi-Asl V, Kajorncheappunngam S, GangaRao HVS, Gupta RK. Dynamic mechanical study of epoxy, epoxy/glass, and glass/epoxy/wood hybrid composites aged in various media. Polym Compos 2009;30:1761-70. doi:10.1002/pc.20741.

[192] Fiore V, Sanfilippo C, Calabrese L. Dynamic Mechanical Behavior Analysis of Flax/Jute FiberReinforced Composites under Salt-Fog Spray Environment. Polymers (Basel) 2020;12:716. doi:10.3390/polym12030716.

[193] Hiroshi Mizumachi HM. Study of Polymer Blends as a Vibration Damper. J Adhes 1970;2:2928. doi:10.1080/0021846708544602.

[194] Huda MS, Drzal LT, Misra M, Mohanty AK. Wood-fiber-reinforced poly(lactic acid) composites: Evaluation of the physicomechanical and morphological properties. J Appl Polym Sci 2006;102:4856-69. doi:10.1002/app.24829.

[195] Montazeri A, Pourshamsian K, Riazian M. Viscoelastic properties and determination of free volume fraction of multi-walled carbon nanotube/epoxy composite using dynamic mechanical thermal analysis. Mater Des 2012;36:408-14. doi:10.1016/j.matdes.2011.11.038.

[196] Chua PS. Dynamic mechanical analysis studies of the interphase. Polym Compos 1987;8:30813. doi:10.1002/pc.750080505.

[197] Kollia A, Kontaxis LC, Papanicolaou GC, Zaoutsos SP. Effect of thermal shock cycling on the quasi-static and dynamic flexural properties of flax fabric-epoxy matrix laminates. J Appl Polym Sci 2019;48529:1-9. doi:10.1002/app.48529. 